\author{
В. К. ВОЛОСЮК， В. В. ПАВЛІКОВ，С. С. ЖИЛА, А. В. ПОПОВ, \\ В. В. КОШАРСЬКИЙ, О. В. ОДОКІЕНКО, В. Г. ЯКОВЛЕВ, Е. О. ЦЕРНЕ, \\ Д. С. ВЛАСЕНКО, А. Д. СОБКОЛОВ
}

\author{
Національний аерокосмічний університет ім. М. С. Жуковського «Харківський \\ авіаційний інститут", Украӥна
}

\title{
ДОСЛІДЖЕННЯ ЯКІСНИХ ПОКАЗНИКІВ ПОЛЯРИЗАЦЙНОЇ СЕЛЕКЦІЇ ОБ'ЄКТІВ НА ФОНІ ПАСИВНИХ ЗАВАД В ПОЛЯРИЗАЦІЙНО-ДОПЛЕРІВСЬКІЙ РАДІОЛОКАЦІЙНІЙ СИСТЕМІ
}

\begin{abstract}
Розглянуто оптимальний алгоритм поляризаџійно-доплерівської селекції иілей на фоні пасивних завад. Проаналізовані поляриметричні властивості розсіяного електромагнітного випромінювання об'єктів. Визначена функиіонально-детермінована математична модель корисного сигналу, структура та кореляційні характеристики внутрішнього випромінювання приймача. Алгоритм оптимальної обробки, синтезований в рамках методу максимуму правдоподібності, розглянуто для двох граничних випадків. Розглянуті та досліджені алгоритмічні дії при обробиі пасивних завад та способи їх компенсачії. Основуючись на отриманих результатах записано вираз для алгоритму компенсації завад віддзеркалених від підстильної поверхні. Отриманий алгоритм здійснює вирівнювання дисперсії вхідних сигналів та за допомогою вагових коефіцієнтів компенсує залишкову дисперсію. На основі розробленого алгоритму формується схема структурна спрощеного оптимального компенсатору пасивних завад. Досліджено особливості обробки корисних сигналів в схемі компенсаиії. Для забезпечення адаптивності сформованого алгоритму коефіцієнт відношення дисперсій знаходиться по результатам, щу надходять з вимірювача дисперсій. Пропонується ввести показники якості поляризаційної селекції об'єктів на тлі підстильної поверхні, щзо поєднують показники ефективності компенсації пасивних завад та показники ефективності обробки корисних сигналів на фоні внутрішніх шумів приймачів. Досліджено відповідні залежності показників від коефіцієнтів корелячії пасивних завад різних поляризачій, а також від коефіцієнтів, щзо характеризують окремо рівень відмінності інтенсивностей сигналів та перешкод у каналах прийому. Досліджено інформативність кожного з показників ефективності поляризаційної селекиії сигналів від коефіцієєнту відношення вхідних дисперсій, коефіцієнту кореляції пасивних завад та коефіцієнту відношення вхідних сигналів. Отримані результати пропонуються використовувати для підвищення якості поляризаційної селекиії об’єктів в радіолокаційних систем наземного та аерокосмічного базування.
\end{abstract}

Ключові слова: метод максимальної правдоподібності; компенсація пасивних завад; поляризаційна селекиія; дисперсія.

\section{Вступ}

При вирішенні задачі селекції корисних сигналів на тлі внутрішніх шумів та пасивних завад потрібно знати відповідні відмінні ознаки. У більшості випадках об'єкти радіолокації, що скелетуються, можуть формувати віддзеркалені сигнали переважно 3 вертикальною або горизонтальною поляризацією. У тому числі об'єктами 3 явно вираженими поляризаційними ознаками можуть бути, наприклад, лінії електропередач, металеві опори, крила літаків та т.д.
Для вирішення задачі ефективної селекції цілей доцільно наряду 3 доплерівськими відмінними ознаками використовувати поляризаційні відмінності. Синтезу різним алгоритмів поляризаційно-доплерівської селекції присвячені роботи $[1,2]$. У роботах значна увага приділяється аналізу алгоритмів поляризаційної селекції цілей та оцінки ефективності селекції в радіолокаційних системах аерокосмічного базування.

Мета роботи полягає в дослідженні показників поляризації селекції об’єктів та їх вплив на проходження корисного сигналу.

(c) В. К. Волосюк, В. В. Павліков, С. С. Жила, А. В. Попов, В. В. Кошарський, О. В. Одокієнко,

В. Г. Яковлєв, Е. О. Церне, Д. С. Власенко, А. Д. Собколов, 2021 


\section{Постановка задачі}

Представимо в класичному вигляді алгоритм оптимальної обробки синтезований в рамках методу правдоподібності, який приймає вигляд відомого кореляційного інтегралу [3-6]:

$\mathrm{Y}\left(\mathrm{t}_{3 \mu}, \vec{\lambda}\right)=\int_{0}^{\mathrm{T}} \int_{0}^{\mathrm{T}}\left\|\mathrm{u}_{\mathrm{i}}\left(\mathrm{t}_{1}\right)\right\|^{\mathrm{T}}\left\|\mathrm{W}_{\mathrm{ij}}\left(\mathrm{t}_{1}, \mathrm{t}_{2}\right)\right\|\left\|\mathrm{s}_{\mathrm{j}}\left(\mathrm{t}_{2}-\mathrm{t}_{3 \mu}, \vec{\lambda}\right)\right\| \mathrm{dt}_{1} \mathrm{dt}_{2}=$ $=\sum_{\mathrm{i}=1}^{2} \sum_{\mathrm{j}=1}^{2} \int_{0}^{\mathrm{T}} \int_{0}^{\mathrm{T}} \mathrm{u}_{\mathrm{i}}\left(\mathrm{t}_{1}\right) \mathrm{W}_{\mathrm{ij}}\left(\mathrm{t}_{1}, \mathrm{t}_{2}\right) \mathrm{s}_{\mathrm{j}}\left(\mathrm{t}_{2}-\mathrm{t}_{3 山}, \vec{\lambda}\right) \mathrm{dt}_{1} \mathrm{dt}_{2}$,

де $\left\|\mathrm{W}_{\mathrm{ij}}\left(\mathrm{t}_{1}, \mathrm{t}_{2}\right)\right\|$ - обернена матриця обернених кореляційних функцій, $\left\|\mathrm{u}_{\mathrm{i}}\left(\mathrm{t}_{1}\right)\right\|$ - сигнал, що приймається, $\left\|\mathrm{s}_{\mathrm{j}}\left(\mathrm{t}_{2}-\mathrm{t}_{\text {зц }}, \vec{\lambda}\right)\right\|-$ огинаюча, що представляє широкий клас сигналів 3 модуляцією. $\mathrm{t}_{\text {зц }}$ - час затримки, «Т» - знак транспонування.

Векторний параметр $\quad \vec{\lambda}\left[\mathrm{t}_{3}\left(\mathrm{R}_{\mathrm{L}}, v, \mathrm{t}\right), \omega_{\text {дц }}(v), \varphi_{\mathrm{L}}\right]$ містить в собі набір параметрів, що характеризують умови спостереження та стан об'єкта (дальність $\mathrm{R}_{\mathrm{L}}$, швидкість $v$, які пов'язані з часом затримки $\mathrm{t}_{3}$ та доплерівським зсувом частоти $\omega_{\text {дц }}$, а також кутові координати $\varphi_{\text {ц }}$ ).

Сигнал, що приймається, представимо у вигляді адитивної моделі рівняння спостереження $\overrightarrow{\mathrm{u}}(\mathrm{t})=\left\|\mathrm{u}_{\mathrm{k}}(\mathrm{t})\right\|$,

$\left\|\mathrm{u}_{\mathrm{i}}(\mathrm{t})\right\|=\left\|\mathrm{s}_{\mathrm{i}}(\mathrm{t}, \vec{\lambda})\right\|+\left\|\mathrm{n}_{\mathrm{i}}(\mathrm{t})\right\|+\left\|\eta_{\mathrm{i}}(\mathrm{t})\right\|, \mathrm{t} \in(0, \mathrm{~T})$,

де $\overrightarrow{\mathrm{s}}(\mathrm{t}, \vec{\lambda})=\left\|\mathrm{s}_{\mathrm{i}}(\mathrm{t}, \vec{\lambda})\right\|-$ корисний сигнал ортогональних поляризацій $\mathrm{i}=\overline{1,2}=(\mathrm{B}, \Gamma)$, що має функціональнодетерміновану форму відносно змінної часу та параметрів $\vec{\lambda}=\left\|\lambda_{v}\right\|, \overrightarrow{\mathrm{n}}(\mathrm{t})=\left\|\mathrm{n}_{\mathrm{i}}(\mathrm{t})\right\|-$ пасивні завади, що обумовлені радіолокаційними віддзеркаленнями від підстильної поверхні сигналів, що випромінюються, ортогональних поляризацій та прийняті відповідними каналами, $\vec{\eta}(\mathrm{t})=\left\|\eta_{\mathrm{i}}(\mathrm{t})\right\|-$ внутрішні шуми в каналі прийому.

Сигнал, що випромінюється, представимо в загальній математичній формі:

$$
\mathrm{s}_{\mathrm{i}}(\mathrm{t})=\operatorname{Re} \dot{\mathrm{S}}_{0 \mathrm{k}}(\mathrm{t}) \exp \left(\mathrm{j} 2 \pi \mathrm{f}_{0} \mathrm{t}\right),
$$

де $\dot{\mathrm{S}}_{0 \mathrm{i}}(\mathrm{t})$ - функція, яка описує форму комплексної огинаючої сигналу, що випромінюється, $\mathrm{i}=(\mathrm{B}, \Gamma)-$ індекс, що відповідає виду поляризації, $\mathrm{f}_{0}$ - частота несучого коливання. Структура зондуючи сигналів однакова на обох поляризаціях, $\dot{\mathrm{S}}_{01}(\mathrm{t})=\dot{\mathrm{S}}_{02}(\mathrm{t})=\dot{\mathrm{S}}_{0}(\mathrm{t})$.

Вважаємо, що прийняті корисні сигнали різних поляризацій, віддзеркалені від цілей, мають однакову структуру (закон модуляції, затримку, допплерівський зсув частоти та ін.) і відрізняються тільки множником інтенсивності $\gamma$ [7-8],

$$
\mathrm{s}_{\mathrm{B}}(\mathrm{t}, \vec{\lambda})=\gamma \mathrm{s}_{\Gamma}(\mathrm{t}, \vec{\lambda}) .
$$

Сигнали мають повністю функціональнодетерміновану структуру часто називають сигналами 3 відомими параметрами або повністю відомі сигнали. Пасивні завади, які зумовлені віддзеркаленнями сигналу, що випромінюється, від протяжної по просторовим координатам підстильної поверхні, представимо таким виразом

$\mathrm{n}_{\mathrm{i}}(\mathrm{t})=\operatorname{Re} \dot{\mathrm{C}}_{\mathrm{i}} \int_{\mathrm{D}} \dot{\mathrm{G}}(\overrightarrow{\mathrm{r}}, \mathrm{t}) \dot{\mathrm{F}}_{\mathrm{i}}\left(\overrightarrow{\mathrm{r}}_{\mathrm{r}}, \mathrm{t}\right) \dot{\mathrm{S}}_{0 \mathrm{k}}\left[\mathrm{t}-\mathrm{t}_{3}(\mathrm{t}, \overrightarrow{\mathrm{r}})\right] \exp \left\{\mathrm{j} \omega_{0}\left[\mathrm{t}-\mathrm{t}_{3}(\mathrm{t}, \overrightarrow{\mathrm{r}})\right]\right\} \mathrm{dr}$,

де $\overrightarrow{\mathrm{r}}=(\mathrm{x}, \mathrm{y})$ - координати елементів підстильної поверхні, що розсіюють, $\dot{\mathrm{C}}_{\mathrm{i}}-$ коефіцієнт пропорційності, що включає в себе ослаблення сигналів на трасі їх поширення, коефіцієнти передачі антено-фідерних трактів та ін., $\dot{\mathrm{G}}(\overrightarrow{\mathrm{r}}, \mathrm{t})$ - коефіцієнт підсилення антени, $\dot{\mathrm{F}}_{1}-$ комплексний коефіцієнт розсіювання, $\dot{\mathrm{F}}_{1}=\mathrm{dE}_{\mathrm{i} \text { розс. }} / \dot{\mathrm{E}}_{\mathrm{i} \text { пад }} \mathrm{d} \overrightarrow{\mathrm{r}}-$ відношення напруженості розсіючого i падаючого полів на елемент площі $\mathrm{d} \overrightarrow{\mathrm{r}}, \mathrm{t}_{3}(\mathrm{t}, \overrightarrow{\mathrm{r}})$ - час затримки в процесі руху радару.

Комплексний коефіцієнт розсіювання $\dot{\mathrm{F}}_{1}(\overrightarrow{\mathrm{r}}, \mathrm{t}) \epsilon$ випадковою функцією просторових координат поверхні та часу. Віддзеркалені сигнали від підстильної поверхні вважаємо гауссівськими випадковими процесами, які характеризуються матрицею кореляційних функцій,

$$
\begin{aligned}
& \underline{R}_{n}\left(t_{1}, t_{2}\right)=\left\|R_{n ~ i j}\left(t_{1}, t_{2}\right)\right\|= \\
& =\left\|\begin{array}{lll}
\mathrm{R}_{\mathrm{n} 11}\left(\mathrm{t}_{1}, \mathrm{t}_{2}\right)=\left\langle\mathrm{n}_{1}\left(\mathrm{t}_{1}\right) \mathrm{n}_{1}\left(\mathrm{t}_{2}\right)\right\rangle & \mathrm{R}_{\mathrm{n} 12}\left(\mathrm{t}_{1}, \mathrm{t}_{2}\right)=\left\langle\mathrm{n}_{1}\left(\mathrm{t}_{1}\right) \mathrm{n}_{2}\left(\mathrm{t}_{2}\right)\right\rangle \\
\mathrm{R}_{\mathrm{n} 21}\left(\mathrm{t}_{1}, \mathrm{t}_{2}\right)=\left\langle\mathrm{n}_{2}\left(\mathrm{t}_{1}\right) \mathrm{n}_{1}\left(\mathrm{t}_{2}\right)\right\rangle & \mathrm{R}_{\mathrm{n} 22}\left(\mathrm{t}_{1}, \mathrm{t}_{2}\right)=\left\langle\mathrm{n}_{2}\left(\mathrm{t}_{1}\right) \mathrm{n}_{2}\left(\mathrm{t}_{2}\right)\right\rangle
\end{array}\right\|,
\end{aligned}
$$

елементами матриці (6) $є$ кореляційні та взаємно кореляційні функції

$$
\begin{gathered}
\mathrm{R}_{\mathrm{n} \text { ij }}\left(\mathrm{t}_{1}, \mathrm{t}_{2}\right) \approx 0,5_{\mathrm{F}} \mathrm{r}_{\mathrm{G}}\left(\mathrm{t}_{1}, \mathrm{t}_{2}\right) \operatorname{Re} \exp \left\{\mathrm{j} \omega_{0}\left(\mathrm{t}_{1}-\mathrm{t}_{2}\right)\right\} \times \\
\times|\dot{\mathrm{C}}|^{2} \dot{\mathrm{r}}_{\mathrm{Fij}}\left(\mathrm{t}_{1}, \mathrm{t}_{2}\right) \int_{\mathrm{D}} \dot{\mathrm{\sigma}}_{\mathrm{ij}}^{\mathrm{o}}(\overrightarrow{\mathrm{r}}) \dot{\mathrm{G}}\left(\overrightarrow{\mathrm{r}}, \mathrm{t}_{1}\right) \dot{\mathrm{G}}^{*}\left(\overrightarrow{\mathrm{r}}, \mathrm{t}_{2}\right) \times \\
\times \dot{\mathrm{S}}_{0}\left[\mathrm{t}_{1}-\mathrm{t}_{3}\left(\mathrm{t}_{1}, \overrightarrow{\mathrm{r}}\right)\right] \dot{\mathrm{S}}_{0}\left[\mathrm{t}_{2}-\mathrm{t}_{3}\left(\mathrm{t}_{2}, \overrightarrow{\mathrm{r}}\right)\right] \mathrm{d} \overrightarrow{\mathrm{r}},
\end{gathered}
$$

де $\dot{\mathrm{i}}_{\mathrm{Fij}}\left(\mathrm{t}_{1}, \mathrm{t}_{2}\right)$ - нормована кореляційна функція обумовлена елементами поверхні, що хаотично рухаються, $\mathrm{r}_{\mathrm{G}}\left(\mathrm{t}_{1}, \mathrm{t}_{2}\right)$ - нормована кореляційна функція, обумовлена рухом літальних апаратів та наявністю множини швидкостей відносно елементів поверхні в діапазоні кутів заданих діаграмою спрямованості $\dot{\mathrm{G}}\left(\overrightarrow{\mathrm{r}}, \mathrm{t}_{1}\right), \sigma_{\mathrm{ij}}^{\mathrm{o}}$ - елемент коваріаційної матриці розсіювання.

Питома ефективна площа розсіювання визначається таким математичним виразом

$\dot{\sigma}_{\mathrm{ij}}^{\mathrm{o}}(\overrightarrow{\mathrm{r}}) \dot{\mathrm{r}}_{\mathrm{Fij}}\left(\mathrm{t}_{1}, \mathrm{t}_{2}\right)=\int_{\mathrm{D}}\left\langle\dot{\mathrm{F}}_{1}\left(\overrightarrow{\mathrm{r}}, \mathrm{t}_{1}\right) \dot{\mathrm{F}}_{\mathrm{j}}^{*}\left(\overrightarrow{\mathrm{r}}+\vec{\rho}, \mathrm{t}_{2}\right)\right\rangle \exp \left\{\mathrm{j} \overrightarrow{\mathrm{q}}_{\perp} \vec{\rho}\right\} \mathrm{d} \vec{\rho}(8)$ 
де $\overrightarrow{\mathrm{q}}_{\perp}=\left\|\mathrm{q}_{\mathrm{x}}, \mathrm{q}_{\mathrm{y}}\right\|$ - горизонтальна проекція вектору просторових частот.

Вважаючи пасивні завади стаціонарними випадковими процесами, знаходимо їх матрицю кореляційних функцій

$$
\begin{gathered}
\underline{\mathrm{R}}_{\mathrm{n}}\left(\mathrm{t}_{1}-\mathrm{t}_{2}\right) \approx\left\|\mathrm{R}_{\mathrm{n} \mathrm{ij}}\left(\mathrm{t}_{1}-\mathrm{t}_{2}\right)\right\| \approx \\
\approx\left\|\sigma_{\mathrm{ij}}^{\mathrm{o}} \mathrm{r}_{\mathrm{Fij}}\left(\mathrm{t}_{1}-\mathrm{t}_{2}\right) \mathrm{r}_{\mathrm{G}}\left(\mathrm{t}_{1}-\mathrm{t}_{2}\right) \psi_{0}\left(\mathrm{t}_{1}-\mathrm{t}_{2}\right)\right\|,
\end{gathered}
$$

де $\psi_{0}\left(\mathrm{t}_{1}-\mathrm{t}_{2}\right)=0.5 \operatorname{Re}\left\{\exp \left\{\mathrm{j} \omega_{0}\left(\mathrm{t}_{1}-\mathrm{t}_{2}\right)\right\} \dot{\Psi}_{0}\left(\mathrm{t}_{1}-\mathrm{t}_{2}\right)\right\}$,

$$
\dot{\Psi}_{0}\left(\mathrm{t}_{1}-\mathrm{t}_{2}\right)=\int_{-\infty}^{-\infty} \dot{\mathrm{S}}_{0}\left[\mathrm{t}_{1}-\mathrm{t}_{3}\right] \dot{\mathrm{S}}_{0}^{*}\left[\mathrm{t}_{2}-\mathrm{t}_{3}\right] \mathrm{dt}_{3},
$$

- відповідно автокореляційні функції одиничного сигналу і його комплексної огинаючої.

При високій кореляції пасивних завад різних поляризацій нормованих кореляційних функцій $\mathrm{r}_{\mathrm{Fij}}\left(\mathrm{t}_{1}-\mathrm{t}_{2}\right)=\mathrm{r}_{\mathrm{F}}\left(\mathrm{t}_{1}-\mathrm{t}_{2}\right), \quad$ обумовлені елементами поверхні, що хаотично рухаються, практично не залежать від індексів і, j. Результуючу матрицю кореляційних функцій (9) запишемо у наступному вигляді

$$
\begin{gathered}
\mathrm{R}_{\Sigma \mathrm{ij}}\left(\mathrm{t}_{1}-\mathrm{t}_{2}\right)=\left\|\mathrm{R}_{\mathrm{nij}}\left(\mathrm{t}_{1}-\mathrm{t}_{2}\right)\right\|+\left\|\mathrm{R}_{\eta \mathrm{ij}}\left(\mathrm{t}_{1}-\mathrm{t}_{2}\right)\right\|= \\
=\left\|\sigma_{\mathrm{ij}}^{\mathrm{o}} \varphi\left(\mathrm{t}_{1}-\mathrm{t}_{2}\right)\right\|+\left\|0.5 \mathrm{~N}_{0 \eta \mathrm{i}} \delta\left(\mathrm{t}_{1}-\mathrm{t}_{2}\right)\right\|,
\end{gathered}
$$

де $\sigma_{\mathrm{ij}}^{\mathrm{o}}=\mathrm{r}_{\mathrm{ij}} \sqrt{\sigma_{\mathrm{i}}^{\mathrm{o}} \sigma_{\mathrm{j}}^{\mathrm{o}}}, \varphi\left(\mathrm{t}_{1}-\mathrm{t}_{2}\right)=\mathrm{r}_{\mathrm{F}}\left(\mathrm{t}_{1}-\mathrm{t}_{2}\right) \mathrm{r}_{\mathrm{G}}\left(\mathrm{t}_{1}-\mathrm{t}_{2}\right) \times$

$$
\times \psi_{0}\left(\mathrm{t}_{1}-\mathrm{t}_{2}\right)=\psi_{0}(0) \mathrm{r}_{\varphi}\left(\mathrm{t}_{1}-\mathrm{t}_{2}\right),
$$

Нормований коефіцієнт кореляції прийнятих сигналів різних поляризацій,

$$
r_{i j}=\frac{\sigma_{i j}^{o}}{\sqrt{\sigma_{i}^{o} \sigma_{j}^{o}}}=\frac{\int_{D} \dot{\mathrm{R}}_{F i j}(\vec{\rho}) \mathrm{e}^{\mathrm{j} \overrightarrow{\mathrm{q}}_{\perp} \vec{\rho}} \mathrm{d} \vec{\rho}}{\sqrt{\int_{D} \dot{\mathrm{R}}_{\mathrm{Fii}}(\vec{\rho}) \mathrm{e}^{\mathrm{j} \overrightarrow{\mathrm{q}}_{\perp} \vec{\rho}} \mathrm{d} \vec{\rho} \int_{D} \dot{\mathrm{R}}_{\mathrm{Fjj}}(\vec{\rho}) \mathrm{e}^{\mathrm{j} \overrightarrow{\mathrm{q}}_{\perp} \vec{\rho}} \mathrm{d} \vec{\rho}}},
$$

для випадкових неоднорідностей поверхні не тільки при наявності елементів, що хаотично рухаються, а і в статистичному стані.

В подальшому вважаємо, що $\mathrm{r}_{12}=\mathrm{r}_{21}=\mathrm{r}$, при співпадаючих індексах у величинах $\sigma_{\mathrm{ii}}^{\mathrm{o}}=\sigma_{\mathrm{i}}^{\mathrm{o}}$ та $\sigma_{\mathrm{jj}}^{\mathrm{o}}=\sigma_{\mathrm{j}}^{\mathrm{o}}, \quad$ коефіцієнти кореляції $\mathrm{r}_{11}=\mathrm{r}_{22}=1$, a дисперсія відповідних процесів зв'язані наступними виразами

$$
\sigma_{1}^{2}=\sigma_{\mathrm{B}}^{2}=\sigma_{\mathrm{B}}^{\mathrm{o}} \psi_{0}(0) \text { i } \sigma_{2}^{2}=\sigma_{\Gamma}^{2}=\sigma_{\Gamma}^{\mathrm{o}} \psi_{0}(0) \text {. }
$$

Обернена матриця $\underline{\mathrm{W}}\left(\mathrm{t}_{1}, \mathrm{t}_{2}\right)=\left\|\mathrm{W}_{\mathrm{ij}}\left(\mathrm{t}_{1}, \mathrm{t}_{2}\right)\right\|$ обернаних кореляційних функцій в алгоритмі (1) знаходиться 3 інтегрально-матричного рівняння обернення

$$
\int_{0}^{\mathrm{T}} \underline{\mathrm{R}}\left(\mathrm{t}_{1}, \mathrm{t}_{2}\right) \underline{\mathrm{W}}\left(\mathrm{t}_{2}, \mathrm{t}_{3}\right) \mathrm{dt}_{2}=\underline{\mathrm{I}} \delta\left(\mathrm{t}_{1}-\mathrm{t}_{2}\right),
$$

де $\delta\left(\mathrm{t}_{1}-\mathrm{t}_{3}\right)$ - дельта-функція, $\underline{\mathrm{I}}$ - одинична матриця.

В розгорнутому вигляді рівняння (14) прийме наступний вигляд $\sum_{\mathrm{j}=1}^{2} \int_{0}^{\mathrm{T}} \mathrm{W}_{\mathrm{ij}}\left(\mathrm{t}_{1}, \mathrm{t}_{2}\right) \mathrm{R}_{\Sigma \mathrm{jk}}\left(\mathrm{t}_{2}, \mathrm{t}_{3}\right) \mathrm{dt}_{2}=\delta_{\mathrm{ik}} \delta\left(\mathrm{t}_{1}-\mathrm{t}_{3}\right)$,

де $\delta_{\mathrm{ik}}$ - символ Кронекера.

Вважаючи, що завади стаціонарні процеси, перейдемо від рівняння (14) до рівняння згортки

$$
\begin{gathered}
\int_{-\infty}^{\infty} \underline{\mathrm{W}}\left(\mathrm{t}_{1}-\mathrm{t}_{2}\right) \underline{\mathrm{R}}_{\Sigma}\left(\mathrm{t}_{2}-\mathrm{t}_{3}\right) \mathrm{dt} \mathrm{t}_{2}=\underline{\mathrm{I}} \delta\left(\mathrm{t}_{1}-\mathrm{t}_{3}\right) \Rightarrow \\
\Rightarrow \int_{-\infty}^{\infty} \underline{\mathrm{W}}(\tau) \underline{\mathrm{R}}_{\Sigma}(\mathrm{t}-\tau) \mathrm{d} \tau=\underline{\mathrm{I}} \delta(\mathrm{t}),
\end{gathered}
$$

яке можна вирішити, застосувавши перетворення Фур'є

$$
\underline{\mathrm{G}}_{\mathrm{W}}(\omega) \underline{\mathrm{G}}_{\mathrm{R}_{\Sigma}}(\omega)=\underline{\mathrm{I}} \Rightarrow \underline{\mathrm{G}}_{\mathrm{W}}(\omega) \underline{\mathrm{G}}_{\mathrm{R}_{\Sigma}}^{-1}(\omega),
$$

де

$$
\underline{\mathrm{G}}_{\mathrm{R}_{\Sigma}}(\omega)=\mathbb{F}\left\{\underline{\mathrm{R}}_{\Sigma}\left(\mathrm{t}_{1}-\mathrm{t}_{2}\right)\right\}=
$$

$$
=\left\|\begin{array}{ll}
\dot{\mathrm{G}}_{\mathrm{R}_{\Sigma 11}} & \dot{\mathrm{G}}_{\mathrm{R}_{\Sigma 12}} \\
\dot{\mathrm{G}}_{\mathrm{R}_{\Sigma 11}} & \dot{\mathrm{G}}_{\mathrm{R}_{\Sigma 11}}
\end{array}\right\|=\left\|\begin{array}{ll}
\sigma_{1}^{0} \mathrm{G}_{\mathrm{n} 1}(\omega)+0,5 \mathrm{~N}_{0 \eta 1} & \sigma_{12}^{0} \dot{\mathrm{G}}_{\mathrm{n} 12}(\omega) \\
\sigma_{21}^{0} \dot{\mathrm{G}}_{\mathrm{n} 21}(\omega) & \sigma_{2}^{0} \mathrm{G}_{\mathrm{n} 2}(\omega)+0,5 \mathrm{~N}_{0 \eta 2}
\end{array}\right\|,
$$

- матриця енергетичних спектрів завад (спектральна густина потужності, СГП) $\mathbb{F}\{\cdot\}$ - знак прямого перетворення Фур'є.

Елементи матриці енергетичних спектрів завад містять згортки відповідних енергетичних спектрів $\mathrm{G}_{\mathrm{nij}}(\omega)=\mathbb{F}\left\{\mathrm{r}_{\mathrm{Fij}}\left(\mathrm{t}_{1}-\mathrm{t}_{2}\right) \mathrm{r}_{\mathrm{G}}\left(\mathrm{t}_{1}-\mathrm{t}_{2}\right) \psi\left(\mathrm{t}_{1}-\mathrm{t}_{2}\right)\right\}=$

$$
=\mathrm{G}_{\mathrm{Fij}}(\omega) * \mathrm{G}_{\mathrm{G}}(\omega) * \mathrm{G}_{\psi}(\omega) \text {, }
$$

де “*” - знак згортки.

Енергетичні спектри вважаємо не залежними від індексів i, j, тобто на основі $(10,11)$ елементи спектрів можна представити в наступному виді $\mathrm{G}_{\mathrm{nij}}(\omega)=\psi_{0}(0) \mathrm{G}_{\varphi}(\omega), \mathrm{G}_{\varphi}(\omega)=\mathbb{F}\left\{\mathrm{r}_{\varphi}\left(\mathrm{t}_{1}-\mathrm{t}_{2}\right)\right\}$,

В результаті знаходимо обернену матрицю обернених спектрів

$\underline{\dot{G}}_{\mathrm{W}}(\omega)=\left\|\begin{array}{ll}\dot{\mathrm{G}}_{\mathrm{W}_{11}}(\omega) \dot{\mathrm{G}}_{\mathrm{W}_{12}}(\omega) \\ \dot{\mathrm{G}}_{\mathrm{W}_{21}}(\omega) \dot{\mathrm{G}}_{\mathrm{W}_{22}}(\omega)\end{array}\right\|=\frac{1}{\Delta}\left\|\begin{array}{cc}\sigma_{2}^{0} \mathrm{G}_{\mathrm{n} 2}(\omega)+\frac{\mathrm{N}_{0 \eta 2}}{2} & -\sigma_{12}^{0} \dot{\mathrm{G}}_{\mathrm{n} 12}(\omega) \\ -\sigma_{21}^{0} \dot{\mathrm{G}}_{\mathrm{n} 21}(\omega) & \sigma_{1}^{0} \mathrm{G}_{\mathrm{n} 1}(\omega)+\frac{\mathrm{N}_{0 \eta 1}}{2}\end{array}\right\|=$

$=\underline{\mathrm{G}}_{\mathrm{W}}(\omega)=\frac{1}{\Delta}\left\|\begin{array}{ll}\sigma_{2}^{0} \psi_{\text {од }}(0) \mathrm{G}_{\varphi}(\omega)+\frac{\mathrm{N}_{0 \eta 2}}{2} & -\sqrt{\sigma_{1}^{0} \sigma_{2}^{0}} \mathrm{r}_{12} \psi_{\text {од }}(0) \mathrm{G}_{\varphi}(\omega) \\ -\sqrt{\sigma_{1}^{0} \sigma_{2}^{0}} \mathrm{r}_{21} \psi_{\text {од }}(0) \mathrm{G}_{\varphi}(\omega) & \sigma_{1}^{0} \psi_{\text {од }}(0) \mathrm{G}_{\varphi}(\omega)+\frac{\mathrm{N}_{0 \eta 1}}{2}\end{array}\right\|$,

де $\Delta(\omega)$ - визначник матриці енергетичних спектрів.

В спектральній формі алгоритм (1) прийме наступний вигляд

$\dot{\mathrm{Y}}(\mathrm{j} \omega, \vec{\lambda})=\overrightarrow{\dot{\mathrm{U}}}^{\mathrm{T}}(\mathrm{j} \omega) \dot{\mathrm{G}}_{\mathrm{W}}^{*}(\omega) \overrightarrow{\dot{\mathrm{S}}}^{*}(\mathrm{j} \omega, \vec{\lambda})=\sum_{\mathrm{i}=1}^{2} \sum_{\mathrm{j}=1}^{2} \dot{\mathrm{U}}_{\mathrm{i}}(\mathrm{j} \omega) \dot{\mathrm{G}}_{\mathrm{Wij}}^{*}(\omega) \dot{\mathrm{S}}_{\mathrm{j}}^{*}(\mathrm{j} \omega, \vec{\lambda})=$ $=\dot{\mathrm{U}}_{\mathrm{BB}}(j \omega) \mathrm{G}_{\mathrm{W} 11}(\omega) \dot{\mathrm{S}}_{\mathrm{BB}}^{*}(\mathrm{j} \omega, \vec{\lambda})+\dot{\mathrm{U}}_{\mathrm{BB}}(\mathrm{j} \omega) \mathrm{G}_{\mathrm{W}_{12}}^{*}(\omega) \dot{\mathrm{S}}_{\Gamma \Gamma}^{*}(\mathrm{j} \omega, \vec{\lambda})+$ $+\dot{\mathrm{U}}_{\Gamma \Gamma}(\mathrm{j} \omega) \mathrm{G}_{\mathrm{W}_{21}}^{*}(\omega) \dot{\mathrm{S}}_{\mathrm{BB}}^{*}(\mathrm{j} \omega, \vec{\lambda})+\dot{\mathrm{U}}_{\Gamma \Gamma}(\mathrm{j} \omega) \mathrm{G}_{\mathrm{W}_{22}}(\omega) \dot{\mathrm{S}}_{\Gamma \Gamma}^{*}(\mathrm{j} \omega, \vec{\lambda}),(22)$

Запишемо алгоритм (22) в розгорнутому виді 


$$
\begin{aligned}
& \dot{\mathrm{Y}}(\mathrm{j} \omega, \vec{\lambda})=\left\{\dot{\mathrm{U}}_{\mathrm{B}}(\mathrm{j} \omega)\left[\sigma_{2}^{\mathrm{o}} \psi_{0}(0) \mathrm{G}_{\varphi}(\omega)+0.5 \mathrm{~N}_{0 \eta 2}\right] / \Delta-\right. \\
& \left.-\dot{\mathrm{U}}_{\Gamma}(\mathrm{j} \omega)\left[\sqrt{\sigma_{1}^{\mathrm{o}} \sigma_{2}^{\mathrm{o}}} \mathrm{r}_{21} \psi_{0}(0) \mathrm{G}_{\varphi}(\omega)\right] / \Delta\right\} \dot{\mathrm{S}}_{\mathrm{B}}^{*}(\mathrm{j} \omega, \vec{\lambda})+ \\
& +\left\{\dot{\mathrm{U}}_{\Gamma}(\mathrm{j} \omega)\left[\sigma_{1}^{\mathrm{o}} \psi_{0}(0) \mathrm{G}_{\varphi}(\omega)+0.5 \mathrm{~N}_{0 \eta 1}\right] / \Delta-\right. \\
& \left.-\dot{U}_{B}(j \omega)\left[\sqrt{\sigma_{1}^{o} \sigma_{2}^{0}} \mathrm{r}_{12} \psi_{0}(0) \mathrm{G}_{\varphi}(\omega)\right]\right\} \dot{\mathrm{S}}_{\Gamma}^{*}(\mathrm{j} \omega, \vec{\lambda}), \\
& \text { де } \dot{\mathrm{U}}_{\mathrm{B}}(\mathrm{j} \omega)=\mathbb{F}\left\{\mathrm{u}_{1}(\mathrm{t})\right\}, \dot{\mathrm{U}}_{\Gamma}(\mathrm{j} \omega)=\mathbb{F}\left\{\mathrm{u}_{2}(\mathrm{t})\right\} \text {, } \\
& \dot{\mathrm{S}}_{\mathrm{B}}(\mathrm{j} \omega, \vec{\lambda})=\mathbb{F}\left\{\mathrm{s}_{1}(\mathrm{t})\right\}=\gamma \dot{\mathrm{S}}_{\Gamma}(\mathrm{j} \omega, \vec{\lambda})=\gamma \dot{\mathrm{S}}_{0}(\mathrm{j} \omega, \vec{\lambda}) . \\
& \text { Припустити, що в формулі } \\
& \mathrm{N}_{0 \eta 1}=\mathrm{N}_{0 \eta 2}=0 \text {, тоді отримаємо квазіоптимальний } \\
& \text { алгоритм, який має більш очевидну фізичну } \\
& \text { інтерпретацію, } \\
& \dot{\mathrm{Y}}(\mathrm{j} \omega, \vec{\lambda})=\left\{\gamma\left[\sigma_{2}^{\mathrm{o}} \dot{\mathrm{U}}_{\mathrm{B}}(\mathrm{j} \omega)-\sqrt{\sigma_{1}^{\mathrm{o}} \sigma_{2}^{\mathrm{o}}} \mathrm{r}_{21} \dot{\mathrm{U}}_{\Gamma}(\mathrm{j} \omega)\right]-\right. \\
& -\left[\sqrt{\sigma_{1}^{0} \sigma_{2}^{0}} \mathrm{r}_{12} \dot{\mathrm{U}}_{\mathrm{B}}(\mathrm{j} \omega)-\sigma_{1}^{0} \dot{\mathrm{U}}_{\Gamma}(\mathrm{j} \omega)\right] \psi_{0} \mathrm{G}_{\varphi}(\omega) \dot{\mathrm{S}}_{0}^{*}(\mathrm{j} \omega, \vec{\lambda}) / \Delta,
\end{aligned}
$$

вираз в фігурних дужках складається з комбінації трьох різниць, фізичний зміст яких полягає в компенсації пасивних завад за рахунок їх вагового віднімання на різних поляризаціях. Множник $\psi_{0} \mathrm{G}_{\varphi}(\omega) \dot{\mathrm{S}}_{0}^{*}(\mathrm{j} \omega, \vec{\lambda}) / \Delta$ відповідає за узгоджену фільтрацію корисних сигналів (множник $\left.\dot{\mathrm{S}}_{0}^{*}(\mathrm{j} \omega, \vec{\lambda})\right)$ та доплерівську режекцію пасивних завад (множник $\left.\mathrm{G}_{\varphi}(\omega) / \Delta\right)$.

Рівняння (26) можна привести до алгоритму одноразового віднімання, але 3 іншими ваговими коефіцієнтами,

$$
\begin{gathered}
\dot{\mathrm{Y}}(\mathrm{j} \omega, \vec{\lambda})=\left\{\dot{\mathrm{U}}_{\mathrm{B}}(\mathrm{j} \omega)\left[\gamma \sigma_{2}^{\mathrm{o}}-\sqrt{\sigma_{1}^{\mathrm{o}} \sigma_{2}^{\mathrm{o}}} \mathrm{r}_{12}\right]-\right. \\
-\dot{\mathrm{U}}_{\Gamma}(\mathrm{j} \omega)\left[\gamma \sqrt{\sigma_{1}^{\mathrm{o}} \sigma_{2}^{\mathrm{o}}} \mathrm{r}_{21}-\sigma_{1}^{\mathrm{o}}\right] \psi_{0} \mathrm{G}_{\varphi}(\omega) \dot{S}_{0}^{*}(\mathrm{j} \omega, \vec{\lambda}) / \Delta,
\end{gathered}
$$

зазвичай коефіцієнт $\gamma$ невідомий, тоді наближено в алгоритмі (27) можна прийняти його рівним одиниці, $\gamma=1$. Якщо відомо, що корисний сигнал має виражену поляризацією, наприклад, сигнал відбитий від горизонтальних дротів, тоді бажано ввести коефіцієнт $\gamma<1$ або $\gamma \ll 1$.

Зауважимо, що в вагових коефіцієнтах співмножники $\epsilon$ ефективні перерізи розсіяння, що підлягають відповідним адаптивним оцінками (вимірам).

\section{Дослідження показників рівня поляризаційної компенсації пасивних завад}

Пасивні завади, обумовлені віддзеркаленнями від підстильної поверхні, на підставі виду їх кореляційної функції (9), представимо в часовій та спектральній формі наступними виразами

$$
\begin{gathered}
\mathrm{n}_{\mathrm{i}}(\mathrm{t})=\sigma_{\mathrm{i}} v_{\mathrm{i}}(\mathrm{t})=\sqrt{\sigma_{\mathrm{i}}^{\mathrm{o}} \psi_{\text {од }}(0)} v_{\mathrm{i}}(\mathrm{t}), \sigma_{\mathrm{ii}}^{\mathrm{o}}=\sigma_{\mathrm{i}}^{\mathrm{o}} \\
\dot{\mathrm{n}}_{\mathrm{i}}(\mathrm{j} \omega)=\sigma_{\mathrm{i}} \dot{v}_{\mathrm{i}}(\mathrm{j} \omega)=\sqrt{\sigma_{\mathrm{i}}^{\mathrm{o}} \psi_{\text {од }}(0)} \dot{v}_{\mathrm{i}}(\mathrm{j} \omega),
\end{gathered}
$$

де $v_{\mathrm{i}}(\mathrm{t})$ i $\dot{v}_{\mathrm{i}}(\mathrm{j} \omega)$ - випадкові процеси і відповідні спектри з одиничною дисперсією $\sigma_{v i}^{2}=\left\langle v_{i}^{2}(t)\right\rangle=1 \mathrm{i}$ кореляційними функціями

$$
\begin{gathered}
\left\|\left\langle v_{\mathrm{i}}\left(\mathrm{t}_{1}\right) v_{\mathrm{j}}\left(\mathrm{t}_{2}\right)\right\rangle\right\|=\left\|\mathrm{r}_{\mathrm{ij}} \mathrm{r}_{\varphi}\left(\mathrm{t}_{1}-\mathrm{t}_{2}\right)\right\|= \\
=\left\|\begin{array}{ll}
\mathrm{r}_{\varphi}\left(\mathrm{t}_{1}-\mathrm{t}_{2}\right) & \mathrm{r}_{12} \mathrm{r}_{\varphi}\left(\mathrm{t}_{1}-\mathrm{t}_{2}\right) \\
\mathrm{r}_{21} \mathrm{r}_{\varphi}\left(\mathrm{t}_{1}-\mathrm{t}_{2}\right) & \mathrm{r}_{\varphi}\left(\mathrm{t}_{1}-\mathrm{t}_{2}\right)
\end{array}\right\|=\mathrm{r}_{\varphi}\left(\mathrm{t}_{1}-\mathrm{t}_{2}\right)\left\|\begin{array}{ll}
1 & \mathrm{r}_{12} \\
\mathrm{r}_{21} & 1
\end{array}\right\| .
\end{gathered}
$$

Матриця дисперсій $\left\|\sigma_{\mathrm{ij}}^{2}\right\|$ пасивних завад i коваріаційна матриця розсіювання $\left\|\sigma_{\mathrm{ij}}^{0}\right\|$ зв'язані між собою та мають наступний вигляд

$$
\left\|\mathrm{R}_{\mathrm{n}_{\mathrm{ij}}}(0)\right\|=\left\|\begin{array}{|cc}
\sigma_{1}^{2} & \sigma_{12}^{2} \\
\sigma_{21}^{2} & \sigma_{2}^{2}
\end{array}\right\|=\psi_{\text {од }}(0)\left\|\begin{array}{cc}
\sigma_{1}^{0} & \sigma_{12}^{0} \\
\sigma_{21}^{0} & \sigma_{2}^{0}
\end{array}\right\| .
$$

3 урахування припущення про рівність шумів в каналах прийому вертикальної і горизонтальної поляризацій та представлення перешкоджаючих віддзеркалень у вигляді процесів (28), а також при $\gamma=1$ вихідний ефект $\dot{\mathrm{Y}}_{\mathrm{n}}(\mathrm{j} \omega, \vec{\lambda})$ оптимальної системи обробки (27) пасивних завад і внутрішніх шумів (при відсутності сигналів) прийме наступний вигляд

$$
\begin{array}{r}
\dot{\mathrm{Y}}(\mathrm{j} \omega, \vec{\lambda})=\left\{\gamma\left[\sigma_{2}^{\mathrm{o}} \dot{\mathrm{U}}_{\mathrm{B}}(\mathrm{j} \omega)-\sqrt{\sigma_{1}^{\mathrm{o}} \sigma_{2}^{\mathrm{o}}} \mathrm{r}_{21} \dot{\mathrm{U}}_{\Gamma}(\mathrm{j} \omega)\right]-\right. \\
-\left[\sqrt{\sigma_{1}^{\mathrm{o}} \sigma_{2}^{\mathrm{o}}} \mathrm{r}_{12} \dot{\mathrm{U}}_{\mathrm{B}}(\mathrm{j} \omega)-\sigma_{1}^{\mathrm{o}} \dot{\mathrm{U}}_{\Gamma}(\mathrm{j} \omega)\right] \psi_{0} \mathrm{G}_{\varphi}(\omega) \dot{\mathrm{S}}_{0}^{*}(\mathrm{j} \omega, \vec{\lambda}) / \Delta,
\end{array}
$$

розглянемо алгоритм в двох граничних випадках.

У першому випадку вважаємо, що внутрішні шуми $\eta_{\mathrm{i}}(\mathrm{t})=0$ та коефіцієнти кореляції $\mathrm{r}_{12}=\mathrm{r}_{21}=1$, при цьому $\dot{v}_{1}(j \omega)=\dot{v}_{2}(j \omega)=\dot{v}(j \omega)$, тоді відбувається повна компенсація завад, що вказує на працездатність алгоритму, в якому основною операцією $€$ віднімання сигналів різних поляризацій. $\mathrm{Y}(\mathrm{j} \omega)=1 / \Delta\left[\sigma_{1}\left(\sigma_{2}^{2}-\sigma_{1} \sigma_{2}\right)-\sigma_{2}\left(\sigma_{1} \sigma_{2}-\sigma_{1}^{2}\right)\right] \dot{v}_{1}(j \omega) \mathrm{G}_{\varphi}(\omega) \dot{S}_{0}^{*}(j \omega)=0$

У другому граничному випадку вважаємо, що виконується тільки перша умова, $\eta_{\mathrm{i}}(\mathrm{t})=0$, тоді

$$
\dot{\mathrm{Y}}_{\mathrm{n}}(\mathrm{j} \omega)=1 / \Delta\left[\sigma_{1} \dot{\mathrm{v}}_{1}(\mathrm{j} \omega)\left(\sigma_{2}^{2}-\sigma_{1} \sigma_{2} \mathrm{r}_{12}\right)-\sigma_{2} \dot{\mathrm{v}}_{2}(\mathrm{j} \omega)\left(\sigma_{1} \sigma_{2} \mathrm{r}_{21}-\sigma_{1}^{2}\right)\right] \times
$$

$$
\times \mathrm{G}_{\varphi}(\omega) \dot{\mathrm{S}}_{0}^{*}(\mathrm{j} \omega, \vec{\lambda}) .
$$

Вираз (32) показує обробку тільки пасивних завад. Зауважимо, що в даних алгоритмах за доплерівську селекцію в основному відповідає множник

$$
\mathrm{G}_{\varphi}(\omega) \dot{\mathrm{S}}^{*}(\mathrm{j} \omega) / \Delta(\omega),
$$

який містить операції узгодженої фільтрації корисного сигналу при його наявності (множення на $\left.\dot{\mathrm{S}}^{*}(\mathrm{j} \omega)\right)$ та операції спектральної режекції завад 
шляхом декореляції або шляхом створення провалу в амплітудно-частотній характеристиці приймача в області частот зайнятих завадою $\mathrm{G}_{\varphi}(\omega)$ (знаменник

$\Delta(\omega))$. За поляризаційну селекцію в основному відповідає вираз в квадратних дужках і частково структура визначника. Проаналізуємо окремо вираз у квадратних дужках у формулі (32) в часовій області та враховуючи рівняння (28) запишемо в наступному вигляді,

$\Delta \mathrm{n}_{\text {зал }}(\mathrm{t})=\sigma_{1}\left(\sigma_{2}^{2}-\sigma_{1} \sigma_{2} \mathrm{r}_{12}\right) v_{1}(\mathrm{t})-\sigma_{2}\left(\sigma_{1} \sigma_{2} \mathrm{r}_{21}-\sigma_{1}^{2}\right) v_{2}(\mathrm{t})=$ Рис $=\left(\sigma_{2}^{2}-\sigma_{1} \sigma_{2} \mathrm{r}_{12}\right) \mathrm{n}_{1}(\mathrm{t})-\left(\sigma_{1} \sigma_{2} \mathrm{r}_{21}-\sigma_{1}^{2}\right) \mathrm{n}_{2}(\mathrm{t})=\mathrm{an}_{1}(\mathrm{t})-\mathrm{bn}_{2}(\mathrm{t}),(34)$ де $\Delta \mathrm{n}_{\text {зал }}(\mathrm{t})$ - не скомпенсований залишок завади,

$$
\mathrm{a}=\sigma_{2}^{2}-\sigma_{1} \sigma_{2} \mathrm{r}_{12}, \mathrm{~b}=\sigma_{1} \sigma_{2} \mathrm{r}_{21}-\sigma_{1}^{2} .
$$

Також вираз (34) можна записати наступним чином

$\Delta \mathrm{n}_{\text {зал }}(\mathrm{t})=\left[\sigma_{2}^{2} \mathrm{n}_{1}(\mathrm{t})-\sigma_{1} \sigma_{2} \mathrm{r}_{21} \mathrm{n}_{2}(\mathrm{t})\right]-\left[\sigma_{1} \sigma_{2} \mathrm{r}_{12} \mathrm{n}_{1}(\mathrm{t})-\sigma_{1}^{2} \mathrm{n}_{2}(\mathrm{t})\right]=$ $=\sigma_{1} \sigma_{2}^{2}\left[v_{1}(\mathrm{t})-\mathrm{r}_{21} v_{2}(\mathrm{t})\right]-\sigma_{2} \sigma_{1}^{2}\left[\mathrm{r}_{12} v_{1}(\mathrm{t})-\mathrm{v}_{2}(\mathrm{t})\right]$,

для визначення особливостей фізичного сенсу даного алгоритму розглянемо його складові. Перший та другий доданки представляють собою алгоритми взаємної компенсації віддзеркалень завад від підстильної поверхні. Вид обох доданків в (35) свідчать про те, що цей алгоритм вирівнює дисперсії процесів $\mathrm{n}_{1}(\mathrm{t})$ i $\mathrm{n}_{2}(\mathrm{t})$ множенням на відповідні вагові коефіцієнти, а потім отримані процеси віднімає один з одного. Введення вагових множників $\mathrm{r}_{12}$ i $\mathrm{r}_{21}$ мінімізує залишкову дисперсію при взаємній компенсації перешкод $\mathrm{n}_{1}(\mathrm{t})$ i $\mathrm{n}_{2}(\mathrm{t})$.

Знайдемо мінімальну залишкову дисперсію вагової різниці процесів $\mathrm{n}_{1}(\mathrm{t})$ i $\mathrm{n}_{2}(\mathrm{t})$

$$
\begin{gathered}
\sigma_{\text {зал }}^{2}=\left\langle\left[\mathrm{n}_{1}(\mathrm{t})-\mathrm{xn}_{2}(\mathrm{t})\right]^{2}\right\rangle=\left\langle\left[\sigma_{1} v_{1}(\mathrm{t})-\sigma_{2} \mathrm{xv}_{2}(\mathrm{t})\right]^{2}\right\rangle= \\
=\left\langle\sigma_{1}^{2} v_{1}^{2}(\mathrm{t})\right\rangle+\mathrm{x}^{2}\left\langle\sigma_{2}^{2} v_{2}^{2}(\mathrm{t})\right\rangle-2 \sigma_{1} \sigma_{2} \mathrm{x}\left\langle\mathrm{n}_{1}(\mathrm{t}) \mathrm{n}_{2}(\mathrm{t})\right\rangle= \\
=\sigma_{1}^{2}-2 \sigma_{1} \sigma_{2} \mathrm{xr}_{12}+\sigma_{2}^{2} \mathrm{x}^{2}=\min .
\end{gathered}
$$

3 умови $\mathrm{d}_{\text {зал }}^{2} / \mathrm{dx}=0$ знаходимо вагові коефіцієнти $\mathrm{x}=\alpha \mathrm{r}_{12}, \alpha=\sigma_{1} / \sigma_{2}$, тоді

$$
\sigma_{\text {зал }}^{2}=\left\langle\left[\mathrm{n}_{1}(\mathrm{t})-\alpha \mathrm{r}_{12} \mathrm{n}_{2}(\mathrm{t})\right]^{2}\right\rangle=\min .
$$

В результаті отримуємо вираз для найпростішого алгоритму компенсації пасивних завад, який подібно складовим в алгоритмі, в яких ваговій множник $\alpha$ вирівнює дисперсії процесів, що компенсуються і разом 3 множником $\mathrm{r}_{12}$ мінімізує залишкову дисперсію.

На рис. 1 зображена структурна схема спрощеного поляризаційного компенсатору завад, яка також $\epsilon$ схемою простого поляризаційного селектору корисних сигналів відповідно алгоритму представленому вище.

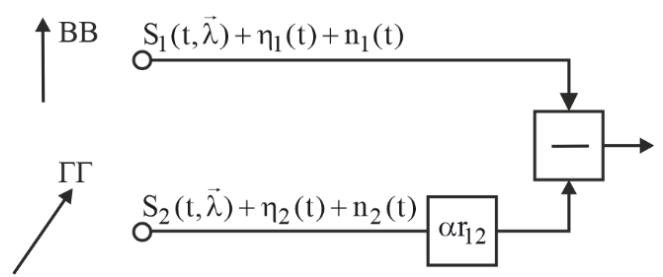

. 1. Структурна схема спрощеного оптимального компенсатору пасивних завад

У синтезованому алгоритмі (35) два доданки відповідають наявності двох операцій компенсації завад, коли один процес віднімається 3 іншого i додатково інший процес віднімається 3 першого 3 ваговими коефіцієнтами $\mathrm{r}_{12}=\mathrm{r}_{21}=\mathrm{r}$. В алгоритмі присутня і третя компенсаційна операція віднімання другої кратності, тобто віднімання різниць процесів, представлених лівим і правим складовими в рівнянні (35). Чим більше коефіцієнти кореляції, тим вище рівень компенсації завад, при малих значеннях цих коефіцієнтів i, зокрема, при $\mathrm{r}_{12}=\mathrm{r}_{21}=0$ знаки складових можуть бути довільними, у цих випадках ефективність компенсації перешкод $є$ низькою.

Так як абсолютні значення дисперсій оцінити не просто, то для технічної реалізації алгоритм доцільно представляти в відносних одиницях у вигляді відношення $\alpha=\sigma_{1} / \sigma_{2}$.

$\Delta \mathrm{n}_{\text {зал }}(\mathrm{t})=\left[\sigma_{2}^{2} \mathrm{n}_{1}(\mathrm{t})-\sigma_{1} \sigma_{2} \mathrm{r}_{21} \mathrm{n}_{2}(\mathrm{t})\right]-\left[\sigma_{1} \sigma_{2} \mathrm{r}_{12} \mathrm{n}_{1}(\mathrm{t})-\sigma_{1}^{2} \mathrm{n}_{2}(\mathrm{t})\right]=$ $=\sigma_{2}^{2}\left\{\left[\mathrm{n}_{1}(\mathrm{t})-\alpha \mathrm{r}_{21} \mathrm{n}_{2}(\mathrm{t})\right]-\alpha\left[\mathrm{r}_{12} \mathrm{n}_{1}(\mathrm{t})-\alpha \mathrm{n}_{2}(\mathrm{t})\right]\right\}$,

у рівнянні (36) множник $\sigma_{2}^{2}$ не має алгоритмічного значення, тому якість компенсації завад оцінюється наступним виразом

$$
\begin{array}{r}
\Delta \xi_{\text {зал }}(\mathrm{t})=\xi_{1}(\mathrm{t})-\alpha \xi_{2}(\mathrm{t})=\left[\mathrm{n}_{1}(\mathrm{t})-\alpha \mathrm{r}_{21} \mathrm{n}_{2}(\mathrm{t})\right]-\alpha\left[\mathrm{r}_{12} \mathrm{n}_{1}(\mathrm{t})-\alpha \mathrm{n}_{2}(\mathrm{t})\right]= \\
=\alpha_{1}\left\{\left[\mathrm{v}_{1}(\mathrm{t})-\mathrm{r}_{21} \mathrm{v}_{2}(\mathrm{t})\right]-\alpha\left[\mathrm{r}_{12} \mathrm{v}_{1}(\mathrm{t})-\mathrm{v}_{2}(\mathrm{t})\right]\right\} . \quad(37)
\end{array}
$$

Алгоритму (37) відповідає дія трійної компенсації пасивних завад. Знайдемо дисперсію залишкової завади після компенсації вважаючи, що $\mathrm{r}_{12}=\mathrm{r}_{21}=\mathrm{r}$,

$\sigma_{\xi_{\text {зал }}^{2}}^{2}=\left\langle\left[\xi_{\text {зал }}(\mathrm{t})\right]^{2}\right\rangle=\left\langle\left[\xi_{1}(\mathrm{t})-\alpha \xi_{2}(\mathrm{t})\right]^{2}\right\rangle=\sigma_{1}^{2}\left\{\left(1-\mathrm{r}^{2}\right)\left[1+\alpha^{2}-2 \alpha \mathrm{r}\right]\right\}$.

В якості коефіцієнта компенсації завад, обумовлених віддзеркаленнями від підстильної поверхні приймаємо функцію оберненого виразу, нормовану на величину $\sigma_{1}^{2}$,

$$
\mu_{\mathrm{n} 1}(\mathrm{r}, \alpha)=1 /\left\{\left(1-\mathrm{r}^{2}\right)\left[1+\alpha^{2}-2 \alpha \mathrm{r}\right]\right\} .
$$


Однак, тут слід виділити три випадки $\alpha=1$, $\alpha>1$ i $\alpha<1$, при яких значення показника компенсації завад $\mu_{\mathrm{n} 1}(\mathrm{r}, \alpha)$ істотно різні. Бажано, щоб в цих випадках при взаємно обернених значеннях $\alpha$ i $\alpha / 1$ значення коефіцієнта компенсації були б однаковими, так як канали прийому сигналів різних поляризацій повинні бути в рівних умовах. Такий показник можна отримати, якщо порівнювати (нормувати) дисперсію залишкової завади з дисперсією завади в тому каналі, в якому вона більше. При $\alpha>1$ величина $\sigma_{1}^{2}>\sigma_{2}^{2}$, тобто дисперсія завад на вертикальній поляризації більше, ніж дисперсія завад на горизонтальній, доцільне нормування, $\mu_{\mathrm{n} 1}(\mathrm{r}, \alpha)=\sigma_{\text {зал }}^{2} / \sigma_{1}^{2}$, а при $\alpha<1, \quad \sigma_{2}^{2}>\sigma_{1}^{2}, \quad \mu_{\mathrm{n} 2}(\mathrm{r}, \alpha)=\sigma_{\text {зал }}^{2} / \sigma_{2}^{2}$. При $\alpha<1$ введемо $\beta=1 / \alpha$ для нормування на більшу дисперсію, тобто на $\sigma_{2}^{2}$, при цьому отримаємо вираз $\sigma_{\text {зал }}^{2}=\sigma_{2}^{2}\left\{\left(1-\mathrm{r}^{2}\right)\left[1+\beta^{2}-2 \beta \mathrm{r}\right]\right\}=\sigma_{2}^{2}\left\{\left(1-\mathrm{r}^{2}\right)\left[\left(1+\alpha^{2}-2 \alpha \mathrm{r}\right) / \alpha^{2}\right]\right\}$.

Запишемо коефіцієнт компенсації, отриманий в результаті нормування дисперсії залишкових завад на дисперсію завад з горизонтальною поляризацією,

$$
\mu_{\mathrm{n} 2}(\mathrm{r}, \alpha)=\alpha^{2} /\left\{\left(1-\mathrm{r}^{2}\right)\left[1+\alpha^{2}-2 \alpha \mathrm{r}\right]\right\} \text {. }
$$

Введемо середній коефіцієнт компенсації для коректного поєднання випадків $\alpha>1$ та $\alpha<1$, а також відповідного нормування на різні величини $\sigma_{1}^{2}$ i $\sigma_{2}^{2}$, який має одинакові значення при значеннях $\alpha$ та $1 / \alpha .$, рис. 2 ,

$$
\begin{aligned}
& \mu_{\mathrm{n}}(\mathrm{r}, \alpha)=\left[\mu_{\mathrm{n} 1}(\mathrm{r}, \alpha)+\mu_{\mathrm{n} 2}(\mathrm{r}, \alpha)\right] / 2= \\
& =\left(1+\alpha^{2}\right) /\left\{2\left(1-\mathrm{r}^{2}\right)\left[1+\alpha^{2}-2 \alpha \mathrm{r}\right]\right\} .
\end{aligned}
$$

\section{Дослідження показників рівня поляризаційної селекції корисних сигналів}

Розглянемо як "проходить" через цей алгоритм (23) корисний сигнал (25), вважаючи, що завади відсутні, тобто

$$
\begin{gathered}
\dot{\mathrm{U}}_{\mathrm{B}}(\mathrm{j} \omega)=\dot{\mathrm{S}}_{\mathrm{B}}(\mathrm{j} \omega), \dot{\mathrm{U}}_{\Gamma}(\mathrm{j} \omega)=\dot{\mathrm{S}}_{\Gamma}(\mathrm{j} \omega), \\
\dot{\mathrm{S}}_{\mathrm{B}}(\mathrm{j} \omega)=\gamma \dot{\mathrm{S}}_{\Gamma}(\mathrm{j} \omega)=\gamma \dot{\mathrm{S}}_{0}(\mathrm{j} \omega),
\end{gathered}
$$

Виключимо для простоти 3 алгоритму (23) складові $\mathrm{N}_{0 \eta \mathrm{i}} / 2$ (в загальному випадку їх виключати не можна), перейдемо до спрощених алгоритмів $(26,27)$ по відношенню тільки до проходження корисних сигналів.

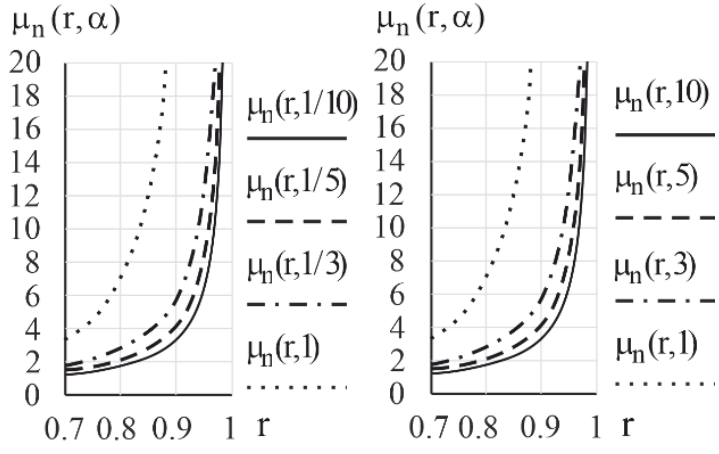

Рис. 2. Коефіцієнти $\mu_{\mathrm{n}}(\mathrm{r}, \alpha)$ при $\alpha<1$ та $\alpha>1$

Тоді сигнальну частину (без завад) вихідного ефекту запишемо в наступному вигляді

$\dot{\mathrm{Y}}_{\mathrm{S}}(\mathrm{j} \omega)=\left\{\dot{\mathrm{S}}_{\mathrm{B}}(\mathrm{j} \omega)\left[\gamma \sigma_{2}^{0}-\sqrt{\sigma_{1}^{0} \sigma_{2}^{0}} \mathrm{r}_{12}\right]-\dot{\mathrm{S}}_{\Gamma}(\mathrm{j} \omega)\left[\gamma \sqrt{\sigma_{1}^{0} \sigma_{2}^{0}} \mathrm{r}_{21}-\sigma_{1}^{0}\right]\right\} \times$

$$
\times\left[\psi_{0}(0) \mathrm{G}_{\varphi}(\omega) \dot{\mathrm{S}}_{0}^{*}(\mathrm{j} \omega, \vec{\lambda})\right] / \Delta=
$$

$=\left[\dot{\mathrm{S}}_{\mathrm{B}}(\mathrm{j} \omega)\left(\gamma \sigma_{2}^{2}-\sigma_{1} \sigma_{2} \mathrm{r}_{12}\right)-\dot{\mathrm{S}}_{\Gamma}(\mathrm{j} \omega)\left(\gamma \sigma_{1} \sigma_{2} \mathrm{r}_{21}-\sigma_{1}^{0}\right)\right] \mathrm{G}_{\varphi}(\omega) \dot{\mathrm{S}}_{0}^{*}(\mathrm{j} \omega) / \Delta .(43)$

Враховуючи рівняння (25) отримаємо наступний вираз для вхідного ефекту $\dot{\mathrm{Y}}_{\mathrm{s}}(\mathrm{j} \omega)$,

$\dot{\mathrm{Y}}_{\mathrm{s}}(\mathrm{j} \omega)=\left\{\left[\gamma\left(\gamma \sigma_{2}^{2}-\sigma_{1} \sigma_{2} \mathrm{r}_{12}\right)+\left(\sigma_{1}^{2}-\gamma \sigma_{1} \sigma_{2} \mathrm{r}_{21}\right)\right] \mathrm{G}_{\varphi}(\omega)\left|\dot{\mathrm{S}}_{0}(\mathrm{j} \omega)\right|^{2}\right\} / \Delta$.

Зауважимо, що коефіцієнти кореляції $\mathrm{r}_{12}, \mathrm{r}_{21}$ значною мірою впливають на рівень компенсації пасивних завад при їх ваговому відніманні. При оцінці рівня проходження корисних сигналів, яка тим вище, чим більша різниця в значеннях величин $\alpha$ i $\gamma$, тобто $\alpha-\gamma$, коефіцієнти наближено можна вважати рівними одиниці, $\mathrm{r}_{12}=\mathrm{r}_{21} \approx 1$. Так вплив коефіцієнтів незначний на рівень проходження корисних сигналів у порівнянні 3 впливом коефіцієнтів $\alpha$ i $\gamma$, тоді при $\mathrm{r}_{12}=\mathrm{r}_{21}=1$, отримаємо

$$
\dot{\mathrm{Y}}_{\mathrm{S}}(\mathrm{j} \omega)=(1 / \Delta) \sigma_{2}^{2}(\gamma-\alpha)^{2} \mathrm{G}_{\varphi}(\omega)\left|\dot{\mathrm{S}}_{0}(\mathrm{j} \omega)\right|^{2},
$$

Можливі показники рівня проходження корисних сигналів через поляризаційний компенсатор завад розглянемо в трьох варіантах.

Перший варіант випливає 3 аналізу формули (47) рівень проходження (поляризаційної селекції) тільки корисного сигналу можна характеризувати по амплітуді та потужності відповідно коефіцієнтами

$$
\mu_{\mathrm{s}}=(\gamma-\alpha)^{2}, \mu_{\mathrm{s}}^{2} .
$$

Рівень селекції корисних сигналів буде тим більше, чим більше різниця коефіцієнтів $\gamma-\alpha$, що характеризують рівень відмінності по амплітуді сигналів та завад в каналах прийому сигналів різних поляризацій. При $\gamma=\alpha$ відбувається компенсація (продавлення) не тільки завад але i корисних сигналів. Даний показник селекції фізичний, але не 
завжди дає об'єктивну інформацію про якість рішення задачі, яка розглядується. Так якщо коефіцієнти $\gamma$ і $\alpha$ більші одиниці, то показник може приймати більші значення, а якщо менше одиниці, то малі. Так як канали різних поляризацій розглядаються в рівних умовах, то відповідний показник повинен бути симетричним. Так, якщо замість відношення $\gamma=\mathrm{s}_{1}(\mathrm{t}) / \mathrm{s}_{2}(\mathrm{t}) \quad$ прийняти оберненого відношення $\gamma^{-1}=\mathrm{s}_{2}(\mathrm{t}) / \mathrm{s}_{1}(\mathrm{t}), \quad$ тоді вданій симетричній ситуації показник селекції не повинен зміниться, але, як видно, різниця $\gamma-\alpha$ при значеннях $\gamma$ більших і менших одиниці буде різною.

Другий варіант представляє собою нормований показник

$$
\mu_{\mathrm{s}}=\left|\frac{\gamma-\alpha}{|\gamma|+|\alpha|}\right|, 0 \leq \mu_{\mathrm{s}} \leq 1 .
$$

Розділивши чисельник і знаменник на величину $\gamma$ або величину $\alpha$, то отримаємо рівноцінні показники

$$
\mu_{\mathrm{s}}=\left|\frac{\gamma-\alpha}{|\gamma|+|\alpha|}\right|=\left|\gamma\left(1-\frac{\alpha}{\gamma}\right) / \gamma\left(1+\left|\frac{\alpha}{\gamma}\right|\right)\right|=\left|\frac{1-\beta}{1+|\beta|}\right| .
$$

Ввівши обернені величини $\gamma_{1}=1 / \gamma$ або $\alpha_{1}=1 / \alpha$ отримуємо показники, які будуть рівноцінними попереднім.

В загальному випадку показник рівня селекції сигналів по амплітуді можна записати в наступному виді

$$
\mu_{\mathrm{s}}=\left|\frac{\gamma-\alpha}{|\gamma|+|\alpha|}\right|==\left|\frac{1-\beta}{1+|\beta|}\right| .
$$

На рис. 3 показаний графік функції (48) в залежності від коефіцієнту $\beta$.

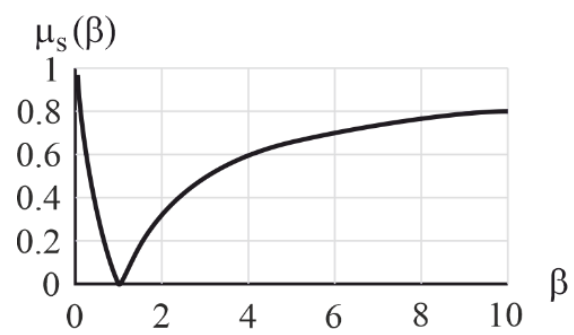

Рис. 3. Показник ефективності селекції корисних сигналів при відсутності перешкод

При $\beta=1$, тобто при $\alpha=\gamma$ в різних каналах, або $\alpha=1 / \gamma_{1}$ в одному з каналів, компенсуються не тільки пасивні завади, але і корисні сигнали різних поляризацій, а рівень селекції корисних сигналів буде нульовим. Рівень селекції буде тим більшим, чим більше $\beta$ при $\beta>1$, або чим менше при $\beta<1$. Значення $\beta$ і $\beta_{1}=1 / \beta$ повинні бути рівноцінними та забезпечувати симетричність показника рівня селекції, як видно з графіка представленого на рис. 3 даній властивості симетрії запропонований коефіцієнт селекції задовольняє, $\mu \mathrm{s}(\beta)=\mu \mathrm{s}(1 / \beta)$.

Розглянуті вище показники рівня селекції, дають можливість охарактеризувати процес проходження корисного сигналу 3 входу поляризаційного селектору на вихід. Для повноти характеристики якості передачі сигналу знання даних характеристик недостатньо, тому розроблено третій варіант показників, які враховують проходження внутрішніх шумів, тобто, характеристики, що враховують зміну відношення по потужності (або енергії) корисного сигналу та шуму. Вважаючи потужності шумів в каналах прийому сигналів різних поляризацій однаковими відповідно маємо наступні відношення сигнал/шум по потужності,

$$
v_{1}=\mathrm{P}_{\mathrm{s} 1} / \mathrm{P}_{\eta}=\gamma^{2} \mathrm{P}_{\mathrm{s} 2} / \mathrm{P}_{\eta}=\gamma^{2} v_{2}, v_{2}=\mathrm{P}_{\mathrm{s} 2} / \mathrm{P}_{\eta} .
$$

Для дослідження зміни відношення в алгоритмах додаємо до корисних сигналів внутрішні шуми (пасивні перешкоди виключаємо), тобто вважатимемо, що в систему обробки надходять наступні процеси,

$$
\left\{\begin{array}{l}
\mathrm{u}_{\mathrm{BB}}(\mathrm{t})=\mathrm{u}_{1}(\mathrm{t})=\mathrm{s}_{1}(\mathrm{t})+\eta_{1}(\mathrm{t})=\gamma \mathrm{s}_{2}(\mathrm{t})+\eta_{1}(\mathrm{t}) \\
\mathrm{u}_{\Gamma \Gamma}(\mathrm{t})=\mathrm{u}_{2}(\mathrm{t})=\mathrm{s}_{2}(\mathrm{t})+\eta_{2}(\mathrm{t})
\end{array},\right.
$$

Після обробки корисних сигналів алгоритмом (27) отримуємо (в спектральної області) рівняння вихідного ефекту в наступному вигляді,

$$
\begin{gathered}
\dot{\mathrm{Y}}_{\mathrm{s}+\eta}(j \omega)=\dot{\mathrm{Y}}_{\mathrm{s}}(\mathrm{j} \omega)+\dot{\mathrm{Y}}_{\eta}(\mathrm{j} \omega)= \\
=\left\{\left[\dot{\mathrm{S}}_{\mathrm{BB}}(\mathrm{j} \omega)+\dot{\eta}_{1}(j \omega)\right]\left(\gamma \sigma_{2}^{2}-\sigma_{1} \sigma_{2} \mathrm{r}_{12}\right)-\left[\dot{\mathrm{S}}_{\Gamma \Gamma}(j \omega)+\dot{\eta}_{2}(j \omega)\right] \times\right. \\
\left.\times\left(\gamma \sigma_{1} \sigma_{2} \mathrm{r}_{21}-\sigma_{1}^{2}\right)\right\} \mathrm{G}_{\varphi}(\omega) \dot{\mathrm{S}}_{0}^{*}(\mathrm{j} \omega) / \Delta(\omega) .
\end{gathered}
$$

Розглянемо рівняння (51) в часовій області. Для дослідження зміни відношення сигнал/шум тільки поляризаційним селектором досить розглянути алгоритмічну частину виразу (51) в фігурних дужках при $\mathrm{r}_{12}=\mathrm{r}_{21} \approx 1$. Звичайно значення $\gamma$ невідоме, тому в алгоритмі приймем $\gamma=1$,

$$
\begin{aligned}
& \Delta s(t)+\Delta \eta(t)=\sigma_{2}^{2}\left\{\begin{array}{l}
{\left[s_{1}(t)+\eta_{1}(t)-\alpha\left[s_{2}(t)+\eta_{2}(t)\right]\right]-} \\
-\alpha\left[s_{1}(t)+\eta_{1}(t)-\alpha\left[s_{2}(t)+\eta_{2}(t)\right]\right]
\end{array}\right\}= \\
& =\sigma_{2}^{2} s_{2}(t)[1-\alpha][\gamma-\alpha]+\sigma_{2}^{2}[1-\alpha]\left[\eta_{1}(t)-\alpha \eta_{2}(t)\right] . \quad(52)
\end{aligned}
$$

Сигнальна та шумова частина в алгоритмі процесу різниці знаходиться виразами,

$$
\begin{gathered}
\Delta s(t)=\sigma_{2}^{2} s_{2}(t)[1-\alpha][\gamma-\alpha], \\
\Delta \eta(t)=\sigma_{2}^{2}[1-\alpha]\left[\eta_{1}(t)-\alpha \eta_{2}(t)\right] .
\end{gathered}
$$


Після проходження сигналу через систему поляризаційної селекції отримуємо наступні вирази для потужностей корисних сигналів та перешкод,

$$
\begin{gathered}
\mathrm{P}_{\Delta \mathrm{S}}=\overline{\left\{\sigma_{2}^{2} \mathrm{~s}_{2}(\mathrm{t})[1-\alpha][\gamma-\alpha]\right\}^{2}}=\sigma_{2}^{4} \mathrm{P}_{\mathrm{s} 2}(1-\alpha)^{2}(\gamma-\alpha)^{2}, \\
\mathrm{P}_{\Delta \eta}=\overline{\left\{\sigma_{2}^{2}[1-\alpha]\left[\eta_{1}(\mathrm{t})-\alpha \eta_{2}(\mathrm{t})\right]\right\}^{2}}=\sigma_{2}^{4}(1-\alpha)^{2}\left(\mathrm{P}_{\eta 1}+\alpha^{2} \mathrm{P}_{\eta 2}\right)= \\
=\sigma_{2}^{4} \mathrm{P}_{\eta}(1-\alpha)^{2}\left(1+\alpha^{2}\right),
\end{gathered}
$$

де риска з верху означає усереднення за часом.

Враховуючи формули (49), можна зв'язати вихідні відношення сигнал/шум 3 вхідними відношеннями $v_{1}, v_{2}=v_{1} / \gamma^{2}$,

$$
v=\mathrm{P}_{\Delta \mathrm{S}} / \mathrm{P}_{\Delta \eta}=\frac{v_{2}(\gamma-\alpha)^{2}}{1+\alpha^{2}}=\frac{v_{1}(\gamma-\alpha)^{2}}{\gamma^{2}\left(1+\alpha^{2}\right)}
$$

В якості показників рівня поляризаційної вибірки цілей виключно для оцінки якості проходження корисних сигналів та внутрішніх шумів приймемо відношення сигнал/шум на входах системи систем селекції,

$$
\mu_{3}=\mid \begin{aligned}
& \mu_{1}=v / v_{1}=(\gamma-\alpha)^{2} /\left[\gamma^{2}\left(1+\alpha^{2}\right)\right], \gamma>1 \\
& \mu_{2}=v / v_{2}=(\gamma-\alpha)^{2} /\left(1+\alpha^{2}\right), \gamma<1
\end{aligned} .
$$

Перший показник $\mu_{1}$ вибираємо при $|\gamma|>1$, коли відношення сигнал/шум в каналі прийому сигналу вертикальної поляризації більше, чим в каналі прийому сигналів горизонтальної поляризації, тобто $v_{1}=\gamma^{2} v_{2}>v_{2}$.

Другий показник $\mu_{2}$ вибираємо при $|\gamma|<1$, коли корисний сигнал горизонтальної поляризації перевищує сигнал вертикальної поляризації, очевидно, що $0 \leq \mu_{2} \leq 1,0 \leq \mu_{1} \leq 1$.

Відповідно формулі (53) залежність показника від коефіцієнтів $\alpha$ та $\gamma$ представлена на рисунку 4. Для обгрунтування симетрії даного коефіцієнта, який рівноцінно враховує зміни сигналів в обох поляризаційних каналах, на рис. 5 зображені відповідні залежності від обернених значень параметра $\gamma$, тобто від $\gamma^{-1}$.

Розглянемо поведінка графіків на прикладі структурної схеми спрощеного віднімання, представленої на рис. 1. На входах схем селекції, які відповідають алгоритмам (26), (27) потужність корисних сигналів визначається множником $(\gamma-\alpha)^{2}$ в формулі (53), а потужність шумів множником $1+\alpha^{2}$.

При $\gamma=-1$ і $\alpha=-1$ величина $(\gamma-\alpha)^{2}=4$, що свідчить про когерентне складення двох ідентичних коливань різних поляризацій та відповідне збільшення потужності в чотири рази. Потужність внутрішніх шумів подвоюється, тобто $1+\alpha^{2}=2$, що свідчить про некогерентне складення, при цьому відношення внутрішніх шумів $\mu_{1}=\mu_{2}=\mu_{3}=2$, що $є$ максимальним значення відношення показника ефективності селекції корисних сигналі. Мінімальне значення показника ефективності селекції, $\mu_{3}=0$, при $\gamma=\alpha$, коли віднімаються ідентичні сигнали різних поляризацій, тобто відбувається когерентна компенсація.

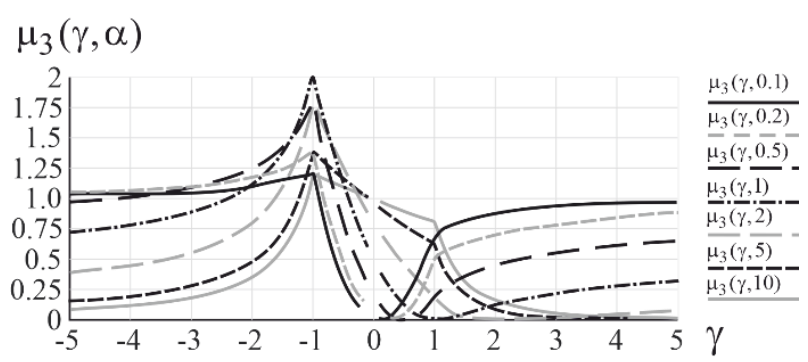

Рис. 4. Безперервна залежність показника ефективності поляризаційної селекції сигналів $\mu_{3}(\gamma, \alpha)$ від $\gamma=\mathrm{s}_{1}(\mathrm{t}) / \mathrm{s}_{2}(\mathrm{t})$ та дискретна від $\alpha=\sigma_{1} / \sigma_{2}$.

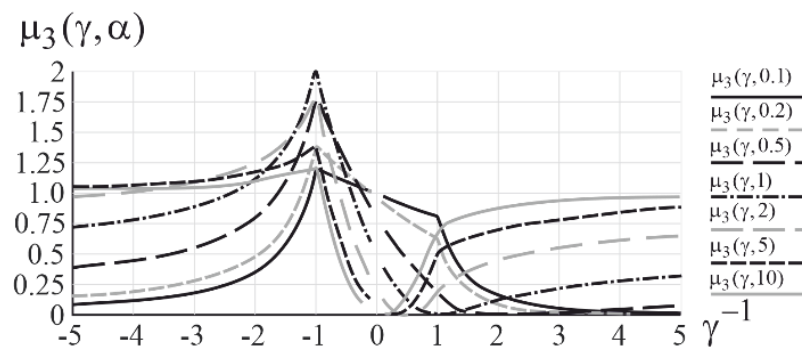

Рис. 5. Безперервна залежність показника ефективності поляризаційної селекції сигналів $\mu_{3}(\gamma, \alpha)$ від $\gamma^{-1}=\mathrm{s}_{2}(\mathrm{t}) / \mathrm{s}_{1}(\mathrm{t})$ та дискретна від

$$
\alpha=\sigma_{1} / \sigma_{2} \text {. }
$$

При $|\gamma|>1$ зі збільшенням коефіцієнта $\gamma$ показник ефективності селекції $\mu_{3}$ збільшується, прагне до межі $1 /\left(1+\alpha^{2}\right)$. При збільшенні коефіцієнта $\alpha$ відбувається зменшення показника ефективності. Видно, що при $|\gamma|>1$ в каналі, що містить операцію множення на $\alpha$, корисний сигнал в $\gamma$ раз менше, а відношення сигнал/шум по потужності в $\gamma^{2}$ раз менше порівняно 3 другим каналом. При множенні на коефіцієнт $\alpha$ сигналу та шуму саме відношення сигнал/шум не змінюється, 
але його вага порівняно з більш високим (в $\gamma^{2}$ раз) відношенням сигнал/шум в другому каналі збільшується, зменшуючи в цілому відношення сигнал/шум на виході селектору і відповідно зменшуючи коефіцієнт $\mu_{3}$. Показник $\mu_{3}$, як i показник (48) обкладає певною симетричністю, яку можна спостерігати при співвідношенні графіків, що представлені на рис. 4 в координатах $\gamma$ та на рис. 5 в координатах $\gamma^{-1}$. В цілому ефективність поляризаційної селекції корисних сигналів можна охарактеризувати добутком коефіцієнта компенсації пасивних завад $\mu_{\mathrm{n}}(\mathrm{r}, \alpha)$ та коефіцієнта, що враховує зміну відношення сигнал/шум на входах та виходах поляризаційного селектору $\mu_{3}(\gamma, \alpha)$

$$
\mu_{4}(r, \alpha, \gamma)=\mu_{n}(r, \alpha) \mu_{3}(\gamma, \alpha) .
$$

Характерні залежності даних коефіцієнтів від параметрів $\mathrm{r}, \alpha, \gamma$ показані на рис. 6-8.

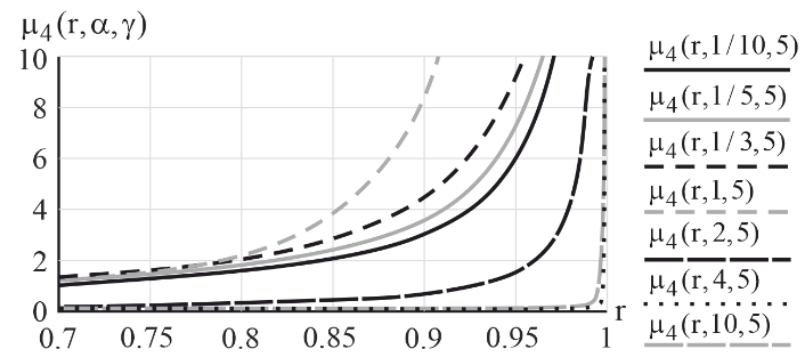

Рис. 6. Безперервна залежність повного показника ефективності поляризаційної селекції сигналів від коефіцієнта кореляції пасивних завад $\mathrm{r}$ та дискретна від коефіцієнта $\gamma=\mathrm{s}_{1}(\mathrm{t}) / \mathrm{s}_{2}(\mathrm{t})$ і коефіцієнта $\alpha=\sigma_{1} / \sigma_{2}$

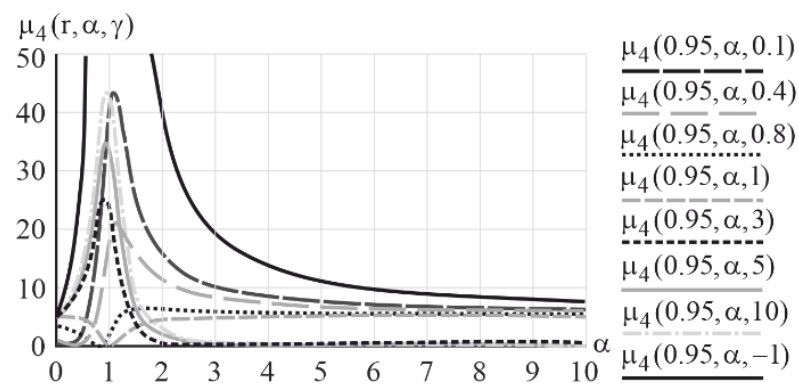

Рис. 7. Безперервна залежність повного показника ефективності поляризаційної селекції сигналів від коефіцієнта $\alpha=\sigma_{1} / \sigma_{2}$ та дискретна від коефіцієнта $\gamma=s_{1}(t) / s_{2}(t)$ і коефіцієнта кореляції пасивних завад $r$

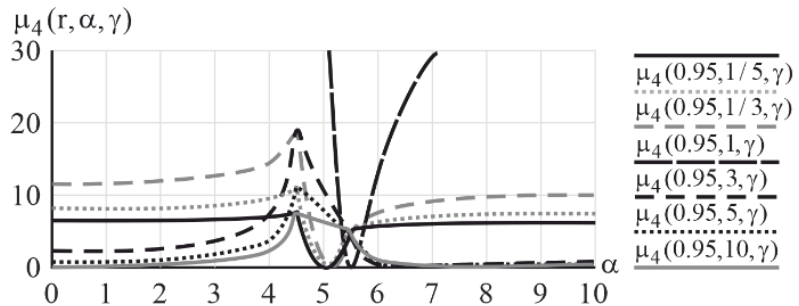

Рис. 8. Безперервна залежність повного показника ефективності поляризаційної селекції сигналів від коефіцієнта $\gamma=\mathrm{s}_{1}(\mathrm{t}) / \mathrm{s}_{2}(\mathrm{t})$ та дискретна

від коефіцієнта $\alpha=\sigma_{1} / \sigma_{2}$ і коефіцієнта кореляції

пасивних завад $r$

Видно, що при коефіцієнтах кореляції пасивних завад $r>0.9$ ефективність поляризаційної селекції $€$ достатньо високою, що свідчить про доцільності іiі використання при рішенні задач виявлення та оцінки параметрів руху наземних та повітряних цілей, вчасності, ліній електропередач на тлі підстильної поверхні.

\section{Висновок}

Досліджено оптимальний алгоритм поляризаційно-доплерівської селекції. Зовнішня математична структура алгоритму має вигляд класичного кореляційного інтеграла у векторноматричній формі. Розглянуто квазіоптимальний варіантах алгоритм, який можна поділити на етапи поляризаційної та спектральної селекції цілей.

Основну увагу приділено поляризаційної селекції цілей, алгоритм якої містить дії формування двох вагових різниць сигналів, що приймаються та третьої різниці між двома попередніми різницями. Запропоновано ввести показники ефективності компенсації пасивних завад та селекції корисних сигналів 3 урахуванням впливу внутрішніх білих шумів приймачів. Наведено та проаналізовано відповідні залежності цих показників від коефіцієнтів кореляції пасивних завад різних поляризацій, а також від коефіцієнтів, що характеризують роздільно рівень відмінностей інтенсивностей сигналів та перешкод у каналах прийому. Показано, що ефективність компенсації пасивних завад максимальна при однаковому рівні інтенсивності у різних поляризаційних каналах i зменшується зі збільшенням різниці. В іншому випадку, ефективність селекції корисних сигналів мінімальна при однакових рівнях інтенсивності в поляризаційних каналах i збільшується зі 
збільшенням відмінностей в інтенсивності як корисних сигналів різних поляризацій так і завад.

Запропоновані результати можуть бути використані для підвищення якості поляризаційної селекції цілей радіолокаційними системами наземного та аерокосмічного базування, наприклад, системи виявлення ліній електропередач вертольотами.

\section{Література}

1. Оптимізація структури багатоканального бортового радару з синтезуванням апертури антени та алгоритмом селекиії ліній електропередач на тлі земної поверхні [Текст] / В.К. Волосюк, В. В. Павликов, С.С. Жила, В.В. Кочарский, О. В. Одокиенко, Е. О. Церне // Авіаційно-космічна техніка і технологія. - 2020. - №5(165). - С. 103-108. DOI: $10.32620 /$ aktt.2020.5.13.

2. Chen, V. The Micro-Doppler Effect in Radar [Text] / V. Chen. - Artech, 2019. - 370 p.

3. Volosyuk, V. K. Statistical Theory of RadioEngineering Systems of Remote Sensing and Radar [Text] / V. K. Volosyuk, V. F. Kravchenko. - M. : Fizmatlit, 2008. - 740 p.

4. UAV synthetic aperture radar system for control of vegetation and soil moisture [Text] / K. S. Lyalin, A. A. Biryuk, A. Y. Sheremet, V. K. Tsvetkov and D. V. Prikhodko // 2018 IEEE Conference of Russian Young Researchers in Electrical and Electronic Engineering (EIConRus) : Materials of the intern. conf., 29 Jan.-1 Feb. 2018. - Moscow, Russia, 2018. - P. 1673 1675.

5. Multiple Bands Dual Polarization Antenna System for Ground Surface State Estimation [Text] /

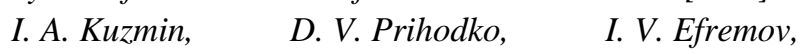
V. I. Oreshkin, A. I. Maksimovskaya // 2019 IEEE Conference of Russian Young Researchers in Electrical and Electronic Engineering (EIConRus) : Materials of the intern. conf., 28-31 Jan. 2019 Saint Petersburg and Moscow, Russia, 2019. - P. 2014-2017.

6. Huang, H. Full Wave Solutions of Multiple Scattering Using Vector Spheroidal Waves and Addition Theorem [Text] / H. Huang, L. Tsang, K. Ding // 2018 IEEE International Symposium on Antennas and Propagation \& USNC/URSI National Radio Science Meeting, 8-13 July 2018. - Boston, USA, 2018. - P. 1753-1754.

7. Cloude, S. R. Polarisation: applications in remote sensing [Text] / S. R. Cloude. - Oxford: Oxford University Press, 2009. - 352 p.
8. A review of target decomposition theorems in radar polarimetry [Text] / S. R. Cloude, E. Pottier // IEEE Transactions on Geoscience and Remote Sensing. - 1996. - No. 2. - P. 498-518.

\section{References}

1. Volosyuk, V. K., Pavlikov, V. V., Zhyla, S. S., Kosharskyi V. V., Odokienko, O. V., Tserne E. O. Optymizatsiya struktury bahatokanal'noho bortovoho radaru z syntezuvannyam apertury anteny ta alhorytmom selektsiyi liniy elektroperedach na tli zemnoyi poverkhni [Optimization of the structure a multi-channel on-board radar with antenna aperture synthesis and algorithm for power line selection on the background of the earth surface]. Aerospace technic and technology, 2020, no. 5(165), pp. 103-108. DOI: 10.32620/aktt.2020.5.13.

2. Chen, V. The Micro-Doppler Effect in Radar. Artech, 2019. 370 p.

3. Volosyuk, V. K., Kravchenko, V. F. Statisticheskaya teoriya radiotekhnicheskikh sistem distantsionnogo zondirovaniya i radiolokatsii [Statistical Theory of Radio-Engineering Systems of Remote Sensing and Radar], Moscow, Fizmatlit Publ., 2008. $740 \mathrm{p}$.

4. Lyalin, K. S., Biryuk, A. A., Sheremet, A. Y., Tsvetkov, V. K. and Prikhodko, D. V. UAV synthetic aperture radar system for control of vegetation and soil moisture. 2018 IEEE Conference of Russian Young Researchers in Electrical and Electronic Engineering (EIConRus), 29 Jan.-1 Feb. 2018, Moscow, Russia, 2018, pp. 1673-1675.

5. Kuzmin, I. A., Prihodko, D. V., Efremov, I. V., Oreshkin, V. I., Maksimovskaya, A. I., Multiple Bands Dual Polarization Antenna System for Ground Surface State Estimation. 2019 IEEE Conference of Russian Young Researchers in Electrical and Electronic Engineering (EIConRus), 28-31 Jan. 2019, Saint Petersburg and Moscow, Russia, 2019, pp. 2014-2017.

6. Huang, H., Tsang, L., Ding, K. Full Wave Solutions of Multiple Scattering Using Vector Spheroidal Waves and Addition Theorem. 2018 IEEE International Symposium on Antennas and Propagation \& USNC/URSI National Radio Science Meeting, 8 July13 July 2018, Boston, USA, 2018, pp. 1753-1754.

7. Cloude, S. R. Polarisation: applications in remote sensing. Oxford, Oxford University Press Publ., 2009. $352 \mathrm{p}$.

8. Cloude, S. R., Pottier, E. A review of target decomposition theorems in radar polarimetry IEEE Transactions on Geoscience and Remote Sensing, 1996, no. 2, pp. 498-518. 


\section{ИССЛЕДОВАНИЕ КАЧЕСТВЕННЫХ ПОКАЗАТЕЛЕЙ ПОЛЯРИЗАЦИОННОЙ СЕЛЕКЦИИ ОБЪЕКТОВ НА ФОНЕ ПАСИВНЫХ ПОМЕХ В ПОЛЯРИЗАЦИОННО-ДОПЛЕРОВСКОЙ РАДИОЛОКАЦИОННОЙ СИСТЕМЕ}

\section{В. К. Волосюк, В. В. Павликов, С. С. Жила, А. В. Попов, В. В. Кочарский, А. В. Одокиенко, В. Г. Яковлев, Э. А. Цернэ, Д. С. Власенко, А. Д. Собколов}

Рассмотрен оптимальный алгоритм поляризационно-доплеровского селекции целей на фоне пассивных помех. Проанализированы поляриметрические свойства рассеянного электромагнитного излучения. Определена функционально-детерминированная математическая модель полезного сигнала, структура и корреляционные характеристики внутреннего излучения приемника. Алгоритм оптимальной обработки, синтезированный в рамках метода максимума правдоподобия, рассмотрен для двух граничных случаев. Рассмотрены и исследованы алгоритмические действия при обработке пассивных помех и способах их компенсации. На основании полученных результатов записано выражение для алгоритма компенсации помех, отраженных от земной поверхности. Полученный алгоритм осуществляет выравнивание дисперсии входных сигналов и посредством весовых коэффициентов компенсирует остаточную дисперсию. На основе разработанного алгоритма формируется структурная структура упрощенного оптимального компенсатора пассивных помех. Исследованы особенности обработки полезных сигналов в схеме компенсации. Для обеспечения адаптивности сложившегося алгоритма коэффициент отношения дисперсий находится по результатам, поступающим из измерителя дисперсий. Предлагается ввести показатели качества поляризационной селекции объектов на фоне подстилающей поверхности, сочетающие показатели эффективности компенсации пассивных помех и показатели эффективности обработки полезных сигналов на фоне внутренних шумов приемников. Исследованы соответствующие зависимости показателей от коэффициентов корреляции пассивных помех разных поляризаций и характеризующих отдельно уровень отличия интенсивностей сигналов и помех в каналах приема. Исследована информативность каждого из показателей эффективности поляризационной селекции сигналов от коэффициента отношения входных дисперсий, коэффициента корреляции пассивных помех и коэффициента отношения входных сигналов. Полученные результаты предлагается использовать для повышения качества поляризационной селекции объектов в радиолокационных системах наземного и аэрокосмического базирования.

Ключевые слова: метод максимальной правдоподобия; компенсация пассивных помех; поляризационная селекция; дисперсия.

\section{RESEARCH QUALITATIVE INDICATORS OF POLARIZATION OF OBJECTS ON THE BACKGROUND OF PASSIVE NOISES IN THE POLARIZATION-DOPPLER RADAR SYSTEM}

\section{Volosyuk, V. Pavlikov, S. Zhyla, A. Popov, V. Kosharskyi, O. Odokienko, V. Yakovlev, E. Tserne, D. Vlasenko, A. Sobkolov}

The optimal algorithm of polarization-Doppler selection of targets against the background of passive interference is considered. The polarimetric properties of scattered electromagnetic radiation of objects. The functionallydetermined mathematical model of the useful signal, structure and correlation characteristics of the internal radiation of the receiver is determined. The algorithm of optimal processing, synthesized within the method of maximum likelihood, is considered for two limit cases. Algorithmic actions in the processing of passive interference and methods of their compensation are considered and investigated. Based on the obtained results, the expression for the algorithm of compensation of interferences reflected from the earth's surface is written. The obtained algorithm equalizes the variance of the input signals and compensates the residual variance with the help of weight coefficients. On the basis of the developed algorithm the scheme of the structurally simplified optimum compensator of passive disturbances is formed. Feature processing of useful signals in the compensation scheme is investigated. To ensure the adaptability of the generated algorithm, the coefficient of the variance ratio is based on the results coming from the variance meter. It is proposed to introduce quality indicators of polarization object selection on the background of the underlying surface, which combines indicators of efficiency of passive interference compensation and indicators of efficiency of useful signal-processing against the background of internal noise of receivers. The corresponding dependence of the indicators on the correlation coefficients of passive interference of different polarizations, as well as on the coefficients that separately characterize the level of difference in signal intensities and interference in the reception channels. The information value of each indicator of the efficiency of polarization signal selection from the ratio of the input variances, the correlation coefficient of passive interference and the ratio of the input signals is investigated. The obtained results are proposed to be used to improve the quality of polarization selection of objects in ground-based and aerospace-based radar systems.

Keywords: maximum likelihood method; passive noise compensation; polarization selection; variance.

Волосюк Валерій Костянтинович - д-р техн. наук, проф., проф. каф. аерокосмічних радіоелектронних систем, Національний аерокосмічний університет ім. М. Є. Жуковського «Харківський авіаційний інститут», Харків, Україна. 
Павліков Володимир Володимирович - д-р техн. наук, проф., проректор з наукової роботи, Національний аерокосмічний університет ім. М. С. Жуковського «Харківський авіаційний інститут», Харків, Україна.

Жила Семен Сергійович - д-р техн. наук, доц., зав. каф. аерокосмічних радіоелектронних систем, Національний аерокосмічний університет ім. М. С. Жуковського «Харківський авіаційний інститут», Харків, Україна.

Попов Анатолій Владиславович - д-р техн. наук, доц., доц. каф. аерокосмічних радіоелектронних систем, Національний аерокосмічний університет ім. М. Є. Жуковського «Харківський авіаційний інститут» Харків, Україна.

Кошарський Володимир Віталійович - асист. каф. аерокосмічних радіоелектронних систем, Національний аерокосмічний університет ім. М. С. Жуковського «Харківський авіаційний інститут», Харків, Україна.

Одокієнко Олексій Володимирович - канд. техн. наук, декан ф-ту Радіоелектроніки, комп’ютерних систем та інфокомунікацій, Національний аерокосмічний університет ім. М. Є. Жуковського «Харківський авіаційний інститут», Харків, Україна.

Яковлєв Віталій Георгійович - доц. каф. аерокосмічних радіоелектронних систем, Національний аерокосмічний університет ім. М. Є. Жуковського «Харківський авіаційний інститут», Харків, Україна.

Церне Едуард Олексійович - асист. каф. аерокосмічних радіоелектронних систем, Національний аерокосмічний університет ім. М. Є. Жуковського «Харківський авіаційний інститут», Харків, Україна.

Власенко Дмитро Сергійович - асист. каф. аерокосмічних радіоелектронних систем, Національний аерокосмічний університет ім. М. С. Жуковського «Харківський авіаційний інститут», Харків, Україна.

Собколов Антон Дмитрович - наук. співроб. каф. аерокосмічних радіоелектронних систем, Національний аерокосмічний університет ім. М. С. Жуковського «Харківський авіаційний інститут», Харків, Україна.

Valerii Volosyuk - Doctor of Technical Science, Professor, Professor of Department of Aerospace RadioElectronic Systems, National Aerospace University "Kharkiv Aviation Institute", Kharkiv, Ukraine, e-mail: v.volosyuk@khai.edu, ORCID: 0000-0002-1442-6235, ResearcherID: A-2021-2019.

Vladimir Pavlikov - Doctor of Technical Science, Professor, Vice Rector for Science, National Aerospace University "Kharkiv Aviation Institute", Kharkiv, Ukraine,

e-mail: v.pavlikov@khai.edu, ORCID: 0000-0002-6370-1758, Scopus Author ID: 23397933100.

Simeon Zhyla - Doctor of Technical Science, head of department of aerospace radio-electronic systems, National Aerospace University "Kharkiv Aviation Institute", Kharkiv, Ukraine, e-mail: s.zhyla@khai.edu, ORCID: 0000-0003-2989-8988, Scopus Author ID: 35106469000.

Anatoliy Popov - Doctor of Technical Science, Associate Professor of Department of Aerospace Radioelectronic Systems, National Aerospace University "Kharkiv Aviation Institute", Kharkiv, Ukraine, e-mail: a.v.popov@khai.edu, ORCID: 0000-0003-0715-3870, Scopus Author ID: 57205357625.

Volodymyr Kosharskyi - Assistant of Department of Aerospace Radio-electronic Systems, National Aerospace University "Kharkiv Aviation Institute", Kharkiv, Ukraine,

e-mail: v.kosharsky@khai.edu, ORCID: 0000-0002-8569-2047, Scopus Author ID: 57218710916.

Oleksii Odokienko - Candidate of Technical Science, Dean of the Faculty of Radio-Electronics, Computer Systems and Infocommunications, National Aerospace University "Kharkiv Aviation Institute", Kharkiv, Ukraine, e-mail: o.odokiienko@khai.edu, ORCID: 0000-0002-5227-1000, Scopus Author ID: 56784405500.

Vitaliy Yakovlev - Associate Professor of Department of Aerospace Radio-electronic Systems, National Aerospace University "Kharkiv Aviation Institute", Kharkiv, Ukraine, e-mail: v.yakovliev@khai.edu, Scopus Author ID: 57197688627.

Eduard Tserne - Assistant of Department of Aerospace Radio-electronic Systems, National Aerospace University "Kharkiv Aviation Institute", Kharkiv, Ukraine, e-mail: e.tserne@khai.edu, ORCID: 0000-0003-0709-2238, Scopus Author ID: 57218704755.

Dmytro Vlasenko - Assistant of Department of Aerospace Radio-electronic Systems, National Aerospace University "Kharkiv Aviation Institute", Kharkiv, Ukraine,

e-mail: d.vlasenko@khai.edu, ORCID: 0000-0002-6118-2173, Scopus Author ID: 57220834070.

Anton Sobkolov - Researcher of Department of Aerospace Radio-electronic Systems, National Aerospace University, Kharkiv, Ukraine, e-mail: a.sobkolov@khai.edu, ORCID: 0000-0001-9356-4187, Scopus Author ID: 57192199954. 